\title{
Analysis of Dynamic Characteristics of Ring Squeeze Film Damper-Rotor System
}

\section{MingMing Shi}

Northwestern Polytechnical University

Yongfeng Yang ( $\nabla$ yyf@nwpu.edu.cn )

Northwestern Polytechnical University https://orcid.org/0000-0003-0402-4440

Jianjun Wang

Institute of China Shipbuilding No. 705

Wangqun Deng

AECC Hunan Aviation Powerplant Research Institute

Desheng Zhang

Highway Bureau of Baotou City

Original Article

Keywords: Squeeze Film Damper, Rotor, Fluid-structure interaction, Wet and dry mode

Posted Date: October 25th, 2021

DOI: https://doi.org/10.21203/rs.3.rs-966661/v1

License: (c) (1) This work is licensed under a Creative Commons Attribution 4.0 International License. Read Full License 


\title{
Analysis of Dynamic Characteristics of Ring Squeeze Film \\ Damper-Rotor System
}

\author{
Mingming Shi ${ }^{a}$, Yongfeng Yang ${ }^{1, a}$, Jianjun Wang ${ }^{b}$, Wangqun Deng ${ }^{c, d}$, Desheng Zhang ${ }^{e}$ \\ (a) Institute of Vibration Engineering, Northwestern Polytechnical University, Xi'an, 710072, China \\ (b) Institute of China Shipbuilding No. 705, Kunming, 650101, China \\ (c) AECC Hunan Aviation Powerplant Research Institute, Zhuzhou, 412002, China \\ (d) Key Laboratory of Aero-engine Vibration Technology, Aero Engine Corporation of China, Zhuzhou,412002, China \\ (e) Highway Bureau of Baotou City, Baotou, 014000, China
}

\begin{abstract}
In this paper, the oil film pressure distribution and fluid-structure coupling dynamic characteristics of the ring squeeze film damper-rotor system are studied and the vibration reduction mechanism of the ring squeeze film damper is revealed, the results of which provide a theoretical basis for the dynamic design of the rotor support system. Based on the theory of hydrodynamic lubrication, the Reynolds equation on the working principle of the floating ring is established. Moreover, the oil film pressure distribution of the inner and outer layers of the floating ring is obtained by adopting the finite difference method. The law of oil film pressure, bearing capacity, and deflection angle with eccentricity and the width-to-diameter ratio is analyzed. Then, the fluid-structure coupling model of a dual-disk over-hung rotor system supported by a floating ring bearing is built by using finite element simulation software. The vibration reduction mechanism and the oil film whirl mechanism of the ring squeeze film damper are revealed according to the analysis of the transient characteristics. The fluid-structure coupling method is used to analyze the influence of oil filling on the dynamic characteristics of the elastic ring. The results of this study show that lubricating oil will make its natural frequency drop.
\end{abstract}

KEYWORDS: Squeeze Film Damper, Rotor, Fluid-structure interaction, Wet and dry mode

\footnotetext{
${ }^{1}$ Corresponding author

E-mail: yyf@nwpu.edu.cn

Address: Institute of Vibration Engineering, Northwestern Polytechnical University, Xi'an, 710072, P. R. China.
} 


\section{Introduction}

The working speed of modern aero-engines is generally above $10000 \mathrm{r} / \mathrm{min}$, while that of some small engines is as high as 40000 to $50000 \mathrm{r} / \mathrm{min}$. For such a high-speed engine, it is necessary to design a specific rotor support system to keep the critical speed of rotation away from the rotor working speed. Rotation speed and additional damping are provided to adjust the vibration of the rotor system. At present, the ring squeeze film damper is widely used in the elastic support device for the vibration and stability control of the aircraft engine rotor system [1-2] Through the elastic support and damping of the squeeze oil film, the external vibration load and amplitude of the system can be reduced, in which the vibration level of the engine is also reduced. Therefore, to study and improve the squeeze film damper ring-rotor system dynamics is an important way to improve overall engine vibration.

Squeeze Film Damper (SFD for short) was developed in the 1960s, and by the 1980s it has been rapidly developed and has had a wider range of applications. Cooper first published an experimental report on the use of the squeeze film damper to reduce rotor vibration, and used the squeeze film damper for the first time. In 1969, the squeeze film damper was put into production at the No. 1 and No. 6-rod bearings of the JT8D engine. The amplitude of the engine was greatly reduced at various engine speeds. Most of the aero-engines have adopted the SFD structure since the 1980s. Although SFD has been widely used in aero-engines, there are still some problems [3-6]. Due to the highly nonlinear oil film force, the mechanical characteristics of the SFD-rotor system may significantly deviate from the design level. The local eccentricity ratio may be larger. Therefore, the rotor vibration response will increase, leading to nonlinear phenomena such as bistable jumps and non-synchronized rotor response. There are some largeamplitude response issues, such as friction between the rotors and rotor fatigue cracks. The service life of the engine will be shortened.

At present, the research on ring squeeze film damper mainly includes the following aspects: First, the hydrodynamic characteristics of the squeeze oil film can be studied theoretically and experimentally by hydrodynamic lubrication theory. Second, the research focuses on the improved squeeze film damper. Third, the dynamic characteristics of the rotor system with ring 
squeeze film damper have been studied theoretically and experimentally from the perspective of rotor dynamics [7].

The theoretical research of the SFD mainly focuses on the solution and modeling of squeeze oil film pressure. The oil film pressure generated by journal precession can be expressed by the relevant theories of fluid mechanics. At the same time, it is solved with the help of the finite element method or finite difference method [8]. In addition, the effects of lubricating oil viscosity, fluid inertia, and multiphase flow can be considered. Andres [9] quantified the mandatory performance of SFD through experiments. The prediction from the new SFD model is in good agreement with the test force coefficients of the two dampers, which proves that the mandatory performance of SFD is related to the lubricant feeding device. Adiletta [10] studied the dynamic characteristics of an unbalanced rigid rotor on a squeeze film damper with a double-lobe wave bearing. The obtained results of which demonstrate how the geometry of the double-lobe wave affects the bifurcation behavior of the system, and changes the length and rotation period of some unstable branches. Andrés [11] studied the response of a rigid rotor system supported by SFD under the short-bearing approximation theory. The study showed that the oil film of SFD can withstand a certain negative pressure. Ferfecki [12] proposed that three methods $(1 \mathrm{D}, 2 \mathrm{D}$, and $3 \mathrm{D})$ were tested and compared to determine the semianalytical relationship describing their distribution in the lubricating film. The principal contribution of this paper is a methodology based on three approaches is developed. This formula describes the distribution of the magnetic induction intensity in the damping gap with the eccentricity and angular position of the rotor journal. As the oil film pressure drops to the saturation pressure of the lubricating oil in the oil cavity, the gas dissolved in the oil will escape and cavitation will appear. If the main component in the cavitation is mainly air, it is called gas cavitation (gaseous cavitation). The research of cavitation mainly focuses on the relationship between the oil film pressure and the increase of the cavitation volume fraction. Studies show that as the proportion of cavitation increases, the oil film pressure gradually decreases. When the volume fraction of cavitation exceeds $85 \%$, the oil film pressure decreases sharply [13]. Liu [14-15] used a rotor tester with a squeeze film damper to study the influence of the static 
eccentricity of the squeeze film damper on the rotor vibration response and combined the design of the squeeze film damper with the rotor dynamics design. Then, the design method of aeroengine squeeze film damper was proposed. Zhou [16-18] used a two-way excitation tester to test the influence of the oil film width and oil film gap of the squeeze film damper on its damping coefficient. In addition, experiments and numerical simulations on the damping mechanism of the floating ring squeeze film damper and the dynamic response of the rotor system were also carried out. Jager [19] verified the rationality of the SFD two-way excitation tester and carried out simulation verification of multi-body dynamics. Therefore, the system has three kinds of multiple solutions, namely, multiple solutions at main resonance, multiple solutions with isolated bifurcation, and multiple solutions with dovetail. Cao [20] established a rotor system model considering the nonlinear characteristics of SFD and analyzed the influence of SFD on the bistable response and non-coordinated precession response of the rotor system. Zhang [21] derived a formula for calculating the damping coefficient of a finite length cylindrical SFD, and conducted a test via the pulse excitation method on an open-ended SFD, which shows that both the oil-supply way and the oil pressure have significant effects on the damping coefficient of the SFD; the pulse excitation method is more suitable for SFDs with a smaller damping coefficient. Ding [22] studied the damping mechanism of the squeeze film damper and showed that through the elastic ring deformation to absorb energy and the boss to control the stiffness, the nonlinearity of SFD can be effectively improved. Hamzehlouia [23] proposed the pressure distribution model of SFD with finite length. By assuming that the shape of velocity distribution is not strongly affected by inertial force, the continuity equation and momentum transport equation of incompressible lubricant are simplified, and the generalized Reynolds equation of hydrodynamic pressure distribution considering inertial effect is obtained. According to the simulation results, the pressure distribution and fluid film reaction forces are significantly influenced by fluid inertia effects even at small and moderate Reynolds numbers. Zapoměl [24] researched a magnetorheological squeeze film damping device which was used to suppress the vibration of a rigid rotor. Chen et al. [25-29] analyzed the influence of SFD oil film damping, oil film stiffness, and elastic ring stiffness on the rotor system through theoretical 
modeling, numerical calculation, finite element analysis, and so on. With the increasing use of low-viscosity lubricating oil, the rotation speed of aero-engine rotors is getting higher and higher, and the Reynolds number of the oil film is also increasing. The inertial force of the oil film plays an important role that cannot be ignored in the motion of the rotor system [30].

Based on the above analysis, this paper studies the oil film flow characteristics of the ring squeeze film damper and the fluid-structure coupling dynamic characteristics of the floating ring-rotor system from the perspective of theory and simulation. It provides a theoretical basis for optimizing the design of the support system, improving the steady state and transient dynamic characteristics of the system, and controlling the vibration.

\section{Physical model and theoretical method}

\subsection{Process of modeling}

The module based on "Rotor Dynamics-beams and the hydrodynamic bearing rotor" was used to model the analysis system. The roulette is simplified as a concentrated mass point fixed on the shaft, and its shape and size are ignored. The centroid of the roulette is set to offset a certain distance from the fixed point to the specified direction (eccentricity). The model includes the rotating shaft, roulette 1 , and roulette 2 , and it is supported by two bearings with floating ring squeeze film dampers. The simplified rotor-bearing system is shown in Figure 1.

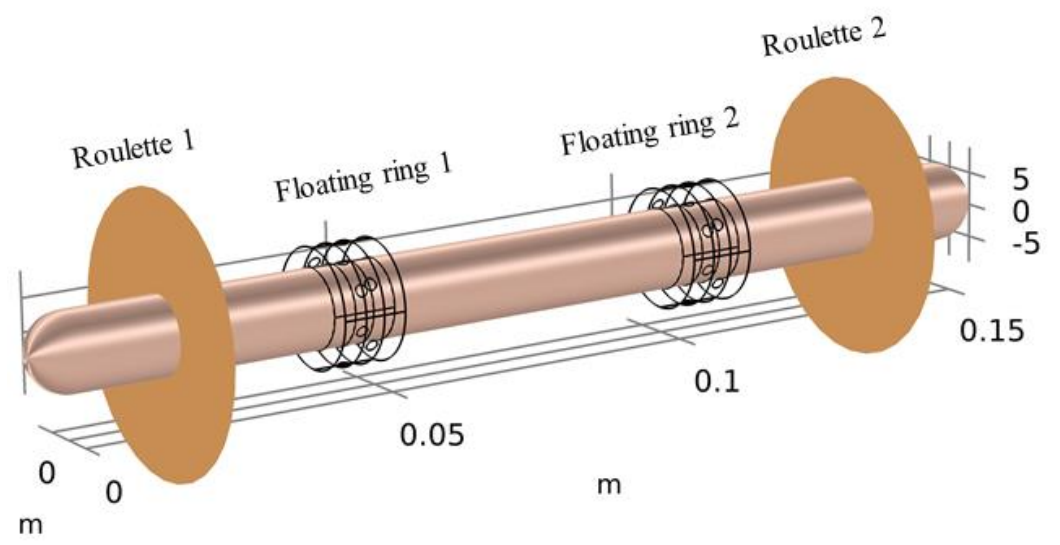

Figure 1 Floating ring bearing-rotor system finite element model.

Six holes are evenly spaced on the whole circumference of the floating ring. At this time, the lubricating oil flow channel between the inner and outer oil chambers is established, as 
shown in Figure 2. Then, the flow rate of lubricating oil between the inner and outer membranes through the oil holes and the pressure transmission characteristics of the oil film can be calculated.

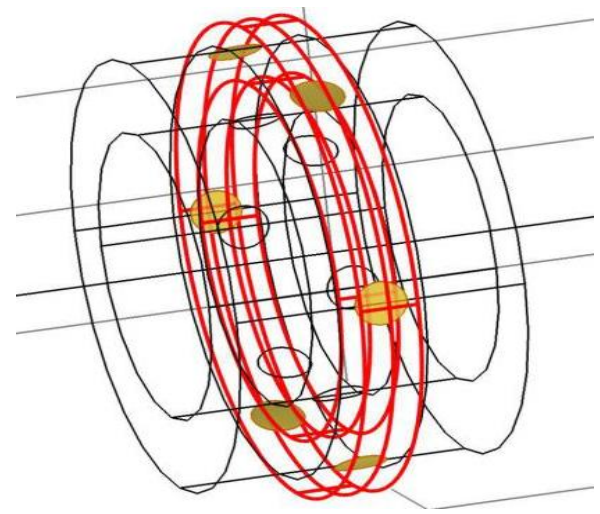

Figure 2 Schematic diagram of the inner and outer oil film channels.

The connection between the rotor and the bearing is based on the "multi-physics coupling characteristics". The hydrodynamic pressure effect is transmitted to the rotor. Therefore, the force transmission between the bearing and the rotor can be calculated. In this simulation calculation, the stress and deformation of the floating ring are not considered. The main focus is on the oil film characteristics of the inner and outer layers of the floating ring.

Table 1 Model parameters of the rotor system.

\begin{tabular}{cccc}
\hline Parameter name & Numerical value & Parameter name & Numerical value \\
\hline Young's modulus & $205 \mathrm{GPa}$ & Poisson's ratio & 0.3 \\
Rotor material density & $7800 \mathrm{~kg} / \mathrm{m}^{3}$ & Length of the rotor, $L$ & $0.15 \mathrm{~m}$ \\
Position of roulette 1 & $0.1 \mathrm{~L}$ & Position of bearing 1 & $0.3 L$ \\
Position of roulette 2 & $0.9 \mathrm{~L}$ & Position of bearing 2 & $0.7 \mathrm{~L}$ \\
Quality of roulette 1 & $1.4 \mathrm{~kg}$ & Quality of roulette 2 & $1.0 \mathrm{~kg}$ \\
Lateral moment of inertia of & $6.3 \times 10^{-4} \mathrm{~kg} \cdot \mathrm{m}^{2}$ & Lateral moment of inertia of & $4.5 \times 10^{-4} \mathrm{~kg} \cdot \mathrm{m}^{2}$ \\
roulette 1 & & roulette 2 & \\
Polar moment of inertia of & $1.26 \times 10^{-5} \mathrm{~kg} \cdot \mathrm{m}^{2}$ & Polar moment of inertia of & roulette 2 \\
roulette 1 & & $9 \times 10^{-4} \mathrm{~kg} \cdot \mathrm{m}^{2}$
\end{tabular}

The geometric parameters, material parameters and settings of the floating ring bearingrotor system are shown in Table 1, and the attribute parameters of the floating ring are shown 
in Table 2.

Table 2 Floating ring bearing parameters.

\begin{tabular}{cccc}
\hline Parameter name & Numerical value & Parameter name & Numerical value \\
\hline Quality of the floating ring & $0.02 \mathrm{~kg}$ & Outer gap & $0.08 \mathrm{~mm}$ \\
Outer radius of the floating ring & $9 \mathrm{~mm}$ & Inner gap & $0.02 \mathrm{~mm}$ \\
Inner radius of the floating ring & $6 \mathrm{~mm}$ & Lubricating oil viscosity & $0.06 \mathrm{~Pa} \cdot \mathrm{s}$ \\
Length of the floating ring & $0.01 \mathrm{~m}$ & - & - \\
\hline
\end{tabular}

The centroids of the two discs are set to offset $6 \times 10^{-7} \mathrm{~m}$ from the center to the z-axis direction. The position is set to be approximately equal to the mass unbalance and eccentricity of the rotor system, and a physical field considering the influence of the gravity of the rotor and the disc is added. The transient analysis time is 0.2 seconds. From the final calculation results, it can be seen that the system has reached a steady state before 0.05 seconds, so the analysis time of 0.2 seconds is appropriate. The time step is $5 \times 10^{-4} \mathrm{~s}$, and the rotor speed is $8000 \mathrm{rad} / \mathrm{min}$. Then, the backward difference formula solution method is selected. The floating ring bearing adopts a full-floating model. Sommerfeld hypothesis is used here, and the solution result can be compared with the Reynolds boundary conditions.

\subsection{Solution of oil film Reynolds equation}

In classical lubrication theory, the Reynolds equation of incompressible fluid in a cylindrical coordinate system is expressed as

$$
\frac{1}{R^{2}} \frac{\partial}{\partial \theta}\left(h^{3} \frac{\partial p}{\partial \theta}\right)+\frac{\partial}{\partial z}\left(h^{3} \frac{\partial p}{\partial z}\right)=6 \mu \cdot \psi \& \frac{\partial h}{\partial \theta}+\frac{\partial h}{\partial t}
$$

where $R$ is the damper radius, $P$ is the oil film pressure, $h$ is the oil film thickness, $\mu$ is the lubricating oil viscosity, $z$ and $\theta$ are the axial and circumferential coordinates, $e$ and $\psi \&$ are the journal eccentricity and deflection angle.

Figure 3 shows the positional relationship of the various parts of the floating ring bearing when the journal whirl is eccentric. The solid line is the initial position, the dashed line is the changed position, $C_{1}$ and $C_{2}$ are the initial thickness of the inner and outer oil film (oil cavity 
gap), $r(\theta)$ is the radial deformation of the floating ring, and $h_{1}$ and $h_{2}$ are the oil film thickness of the inner and outer layers, respectively.

The thickness of the inner oil film can be expressed as

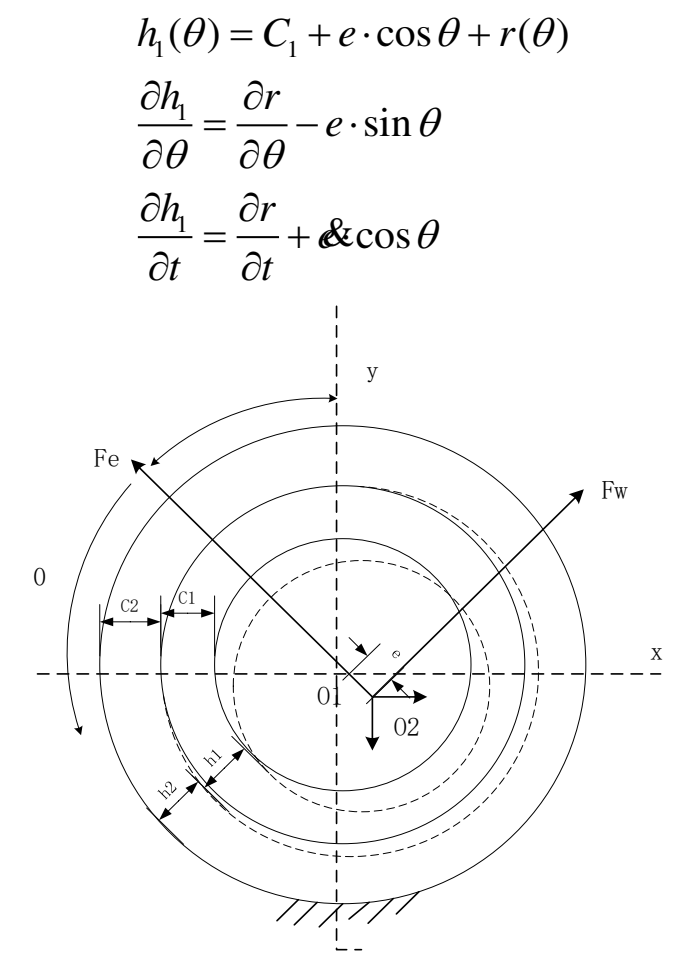

Figure 3 The swirling form of floating ring squeeze film damper.

For the convenience of the finite difference method, the Reynolds equation is dimensionless at first, where $\lambda=2 z / l, H=h / C_{1}, P=p C_{1}^{2} / 2 \Omega \mu r^{2}, l$ is the axial length of the floating ring. The influence of the deformation of the floating ring is ignored here. The dimensionless Reynolds equation of oil film thickness of inner and outer layers of floating ring bearings can be expressed as

$$
\frac{\partial}{\partial \theta}\left(H^{3} \frac{\partial P}{\partial \theta}\right)+\left(\frac{2 R}{l}\right)^{2} \cdot \frac{\partial}{\partial \lambda}\left(H^{3} \frac{\partial P}{\partial \lambda}\right)=6 \cdot \frac{\partial H}{\partial \lambda}+\frac{6}{R c \psi \&} \frac{\partial H}{\partial t}
$$

The oil film pressure inside and outside the oil cavity can be equivalent to the resultant force in two vertical directions, radial force $F_{e}$ and circumferential $F_{\varphi}$, which can be converted into horizontal force $F_{x}$ and vertical force $F_{y}$ through coordinate transformation. Assuming that a single-disk symmetrical rigid rotor is supported by floating ring squeeze film dampers at both ends, the system dynamics equation is expressed as

$$
\left\{\begin{array}{l}
m k_{1} x+c_{1} \&=e m \Omega^{2} \cdot \cos \Omega t+F_{x} \\
k_{2} y+c_{2} \& e m \Omega^{2} \sin \Omega t+F_{y}+G
\end{array}\right.
$$


Where $G=m g$ is half of the gravity of the turntable, $k_{1}$ and $k_{2}$ are the equivalent stiffness of the elastic support, $c_{1}$ and $c_{2}$ are equivalent dampings, $e$ is the eccentricity of the disc, and $\omega$ is the rotation without measuring the excitation frequency. The above equation is dimensionless. If the displacement and time quantities $\tau=\omega t$ and $X=2 x / l$ are introduced, and the simplified equation (4) is substituted into the dimensionless system dynamics equation, it can be expressed as

$$
\left\{\begin{array}{l}
\omega_{1}^{2} X+n_{1} \&=\frac{2 f}{m l} \cos \tau+\frac{2}{m l \Omega^{2}} \cdot F_{x} \\
\omega_{2}^{2} Y+n_{2} \&=\frac{2 f}{m l} \sin \tau+\frac{2}{m l \Omega^{2}} \cdot F_{y}+\frac{2 g}{l \Omega^{2}}
\end{array}\right.
$$

Where $\omega_{i}=\sqrt{k_{i} /\left(m \Omega^{2}\right)}, \quad n_{i}=c_{i} /\left(m \Omega^{2}\right), \quad i=1,2$.

The oil film pressure distribution of the floating ring bearing is solved by using the finite element difference method: the geometric shape of the floating ring bearing is cylindrical. The oil film in the bearing gap is expanded into a two-dimensional rectangle without considering the thickness. Then, several meshes are divided along with the axial and circumferential directions. The pressure value on each grid node is constituted by the difference quotient of each order, which approximately replaces the partial derivative of each order in the Reynolds equation. The continuous partial differential equation is discretized into $n$ algebraic equations. Then the pressure value at each node is solved iteratively. The pressure value obtained by the solution can approximately represent the pressure distribution of the oil film in the oil cavity.

The inner and outer oil films are respectively expanded into rectangular surfaces. The obtained rectangular surface is evenly divided into several grids, as shown in Figure 4. The grid nodes are numbered sequentially in rows and columns. The number of rows along the axis is coded as $j$, and the number of columns along the circumferential direction is coded as $i$. It is uniformly divided into $\mathrm{n}$ grids along the axial direction, $j=1,2, \cdots, n+1$, where $j=1$ and $j=n+1$ are the same point. It is evenly divided into $m$ grids along the circumferential direction, $i=1$, $2, \cdots, m+1$, where $i=1$ and $i=m+1$ are the same node. Then the length of each grid in the axial direction is $\Delta \lambda=\lambda_{j}-\lambda_{j-1}=2 / n$ and the length of each grid in the circumferential direction is $\Delta \theta=\theta_{i}$ $-\theta_{i-1}=2 \pi R / m$. The coordinate number of each node is $(i, j)$, and the pressure value on each node 
is represented by $P_{i, j}$. The partial derivative of the pressure on each node can be approximately equal to the pressure value of its adjacent nodes through the central difference, which can be expressed as

$$
\left(\frac{\partial P}{\partial \theta}\right)_{i, j}=\frac{P_{i+1, j}-P_{i-1, j}}{2 \Delta \theta},\left(\frac{\partial P}{\partial \lambda}\right)_{i, j}=\frac{P_{i, j}-P_{i, j+1}}{2 \Delta \lambda}
$$

Equation(6)is the classical five-point difference format. In order to improve the calculation accuracy, the half-step difference method is adopted, as shown in Figure 5.

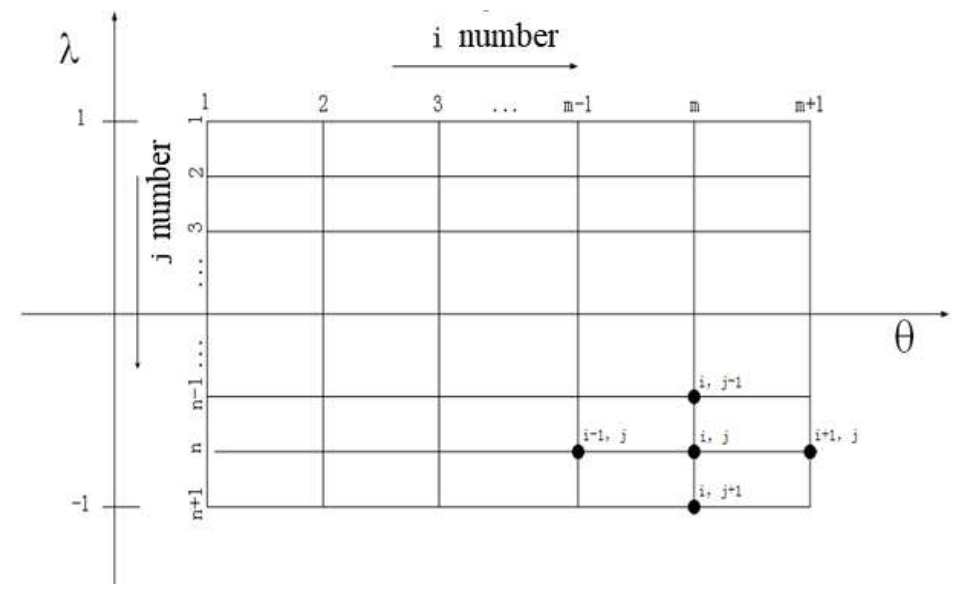

Figure 4 Discrete grid of oil film.

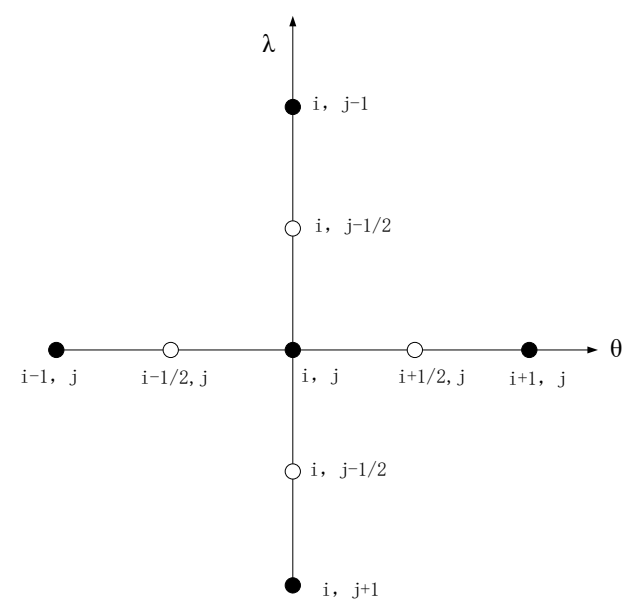

Figure 5 Half-step difference method.

The first derivative is expressed as 


$$
\begin{aligned}
& \left(\frac{\partial P}{\partial \theta}\right)_{i, j}=\frac{P_{i+\frac{1}{2}, j}-P_{i-\frac{1}{2}, j}}{\Delta \theta},\left(\frac{\partial P}{\partial \lambda}\right)_{i, j}=\frac{P_{i, j+\frac{1}{2}}-P_{i, j-\frac{1}{2}}}{\Delta \lambda} \\
& \left(H^{3} \cdot \frac{\partial P}{\partial \theta}\right)_{i+\frac{1}{2}, j}=H_{i+\frac{1}{2}, j}^{3} \cdot \frac{P_{i+1, j}-P_{i, j}}{\Delta \theta},\left(H^{3} \cdot \frac{\partial P}{\partial \theta}\right)_{i-\frac{1}{2}, j}=H_{i-\frac{1}{2}, j}^{3} \cdot \frac{P_{i, j}-P_{i-1, j}}{\Delta \theta} \\
& \left(H^{3} \cdot \frac{\partial P}{\partial \lambda}\right)_{i, j+\frac{1}{2}}=H_{i, j+\frac{1}{2}}^{3} \cdot \frac{P_{i, j+1}-P_{i, j}}{\Delta \lambda},\left(H^{3} \cdot \frac{\partial P}{\partial \lambda}\right)_{i, j-\frac{1}{2}}=H_{i, j-\frac{1}{2}}^{3} \cdot \frac{P_{i, j}-P_{i, j-1}}{\Delta \theta}
\end{aligned}
$$

The second derivative can be expressed as

$$
\begin{gathered}
{\left[\frac{\partial}{\partial \theta}\left(H^{3} \frac{\partial P}{\partial \theta}\right)\right]_{i, j}=\frac{H_{i+\frac{1}{2}, j}^{3} P_{i+1, j}+H_{i-\frac{1}{2}, j}^{3} P_{i-1, j}-\left(H_{i+\frac{1}{2}, j}^{3}+H_{i-\frac{1}{2}, j}^{3}\right) P_{i, j}}{(\Delta \theta)^{2}}} \\
{\left[\frac{\partial}{\partial \lambda}\left(H^{3} \frac{\partial P}{\partial \lambda}\right)\right]_{i, j}=\frac{H_{i, j+\frac{1}{2}}^{3} P_{i, j+1}+H_{i, j-\frac{1}{2}}^{3} P_{i, j-1}-\left(H_{i, j+\frac{1}{2}}^{3}+H_{i, j-\frac{1}{2}}^{3}\right) P_{i, j}}{(\Delta \lambda)^{2}}} \\
\left(\frac{\partial H}{\partial \theta}\right)=\frac{H_{i+\frac{1}{2}, j}-H_{i-\frac{1}{2}, j}}{\Delta \theta}
\end{gathered}
$$

Substituting equations (7), (8), and (9) into (3), the Reynolds equation can be expressed as

$$
A_{i, j}\left(P_{i+1, j}\right)_{1}+B_{i, j}\left(P_{i-1, j}\right)_{1}+C_{i, j}\left(P_{i, j+1}\right)_{1}+D_{i, j}\left(P_{i, j-1}\right)_{1}+E_{i, j}\left(P_{i, j}\right)_{1}=\left(F_{i, j}\right)_{1}
$$

Among them, the following items are included

$$
\begin{aligned}
& A_{i, j}=\frac{H_{i+\frac{1}{2}, j}^{3}}{\Delta \theta^{2}}, B_{i, j}=\frac{H_{i-\frac{1}{2}, j}^{3}}{\Delta \theta^{2}}, C_{i, j}=\left(\frac{2 R}{l}\right)^{2} \frac{H_{i, j+\frac{1}{2}}^{3}}{\Delta \lambda^{2}}, D_{i, j}=\left(\frac{2 R}{l}\right)^{2} \frac{H_{i, j-\frac{1}{2}}^{3}}{\Delta \lambda^{2}}, \\
& \left(F_{i, j}\right)=6 \cdot \frac{H_{i+\frac{1}{2}, j}-H_{i-\frac{1}{2}, j}}{\Delta \theta}+\frac{6 \& \cos \theta}{R l \psi \&} \\
& E_{i, j}=A_{i, j}+B_{i, j}+C_{i, j}+D_{i, j}
\end{aligned}
$$

where $\left(P_{i, j}\right)_{1}$ and $\left(P_{i, j}\right)_{2}$ are the oil film pressures of the inner and outer layers respectively, and $A_{i, j}$ to $F_{i, j}$ are the equation coefficient matrices. The final dimensionless expression of the oil film pressures of the inner and outer layers is expressed as

$$
\left(P_{i, j}\right)=\frac{A_{i, j}\left(P_{i+1, j}\right)+B_{i, j}\left(P_{i-1, j}\right)+C_{i, j}\left(P_{i, j+1}\right)+D_{i, j}\left(P_{i, j-1}\right)-\left(F_{i, j}\right)}{E_{i, j}}
$$

$P_{i, j}$ of all nodes are expressed by the above formula, and a set of $(m-1)(n-1)$ inhomogeneous linear equations can be formed. According to the Reynolds boundary condition: in the circumferential direction of the journal, the lubricating oil film is continuous between the start 
point and the end point of the oil film pressure. After the end point, the oil film splits into a part of liquid and a part of vacuum strip flow. The end point is located at a certain position behind the minimum oil film thickness. At the same time, this position satisfies $P=0$ and $\frac{\partial P}{\partial \theta}=0$. Only the squeezing zone will generate oil film force. After the end point of the oil film pressure, the pressure is all set to 0 . Then some boundary conditions are cited: at $\lambda=0$, and at $\theta=0, P=0$. The equations are solved to get the pressure distribution $P_{i, j}^{1}$, then it is regarded as the initial value of the next iteration. A more accurate solution can be obtained after calculating in the same way. After continuous iteration, the pressure value will infinitely approach the true value. The iteration termination condition can be expressed as

$$
\frac{\sum_{j=2}^{n} \sum_{i=2}^{m}\left|P_{i, j}^{(k)}-P_{i, j}^{(k-1)}\right|}{\sum_{j=2}^{n} \sum_{i=2}^{m}\left|P_{i, j}^{(k)}\right|} \leq \delta, \quad\left(\delta \text { generally go to around } 10^{-3}\right)
$$

From theoretical analysis, it can be seen that the dimensionless oil film pressure $P$ only depends on the two parameters of width-to-diameter ratio and eccentricity. The width-todiameter ratio is generally selected according to actual size requirements and experience. The eccentricity is related to speed. The higher the speed, the smaller the eccentricity. According to the foregoing, the oil film pressure inside and outside the floating ring bearing is calculated. The pressure distribution is shown in Figure 6 and Figure 7. After the cylindrical oil cavity is expanded into a plane, the three-dimensional distribution of the non-dimensional oil film pressure calculated is approximately a continuous parabola. In the wedge-shaped convergence zone, the dimensionless oil film pressure gradually increases from zero to the maximum pressure value, and then the oil film pressure begins to drop to zero. In the divergence zone, the oil film pressure remains at zero, which meets the Reynolds boundary condition. It can be seen that the oil film pressure increases with the increase of the eccentricity. The larger the eccentricity, the greater the oil film pressure. The corresponding oil film damping will also increase, which leads to a subsequent reduction in journal vibration. With the decrease of the eccentricity and the oil film damping, the vibration will increase. 


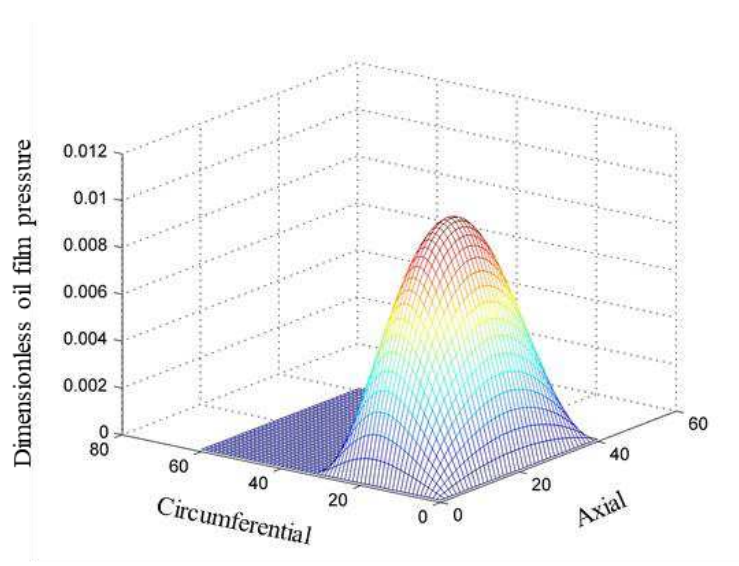

(a) $e=0.1$, ratio $=0.5$

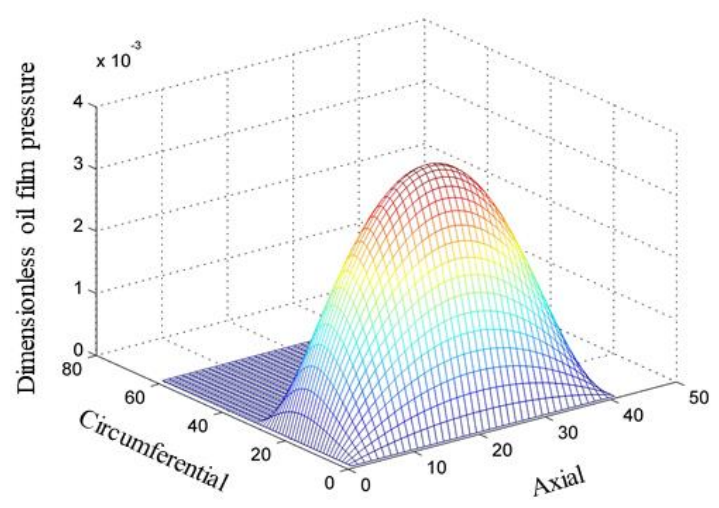

(c) $e=0.1$, ratio $=0.3$

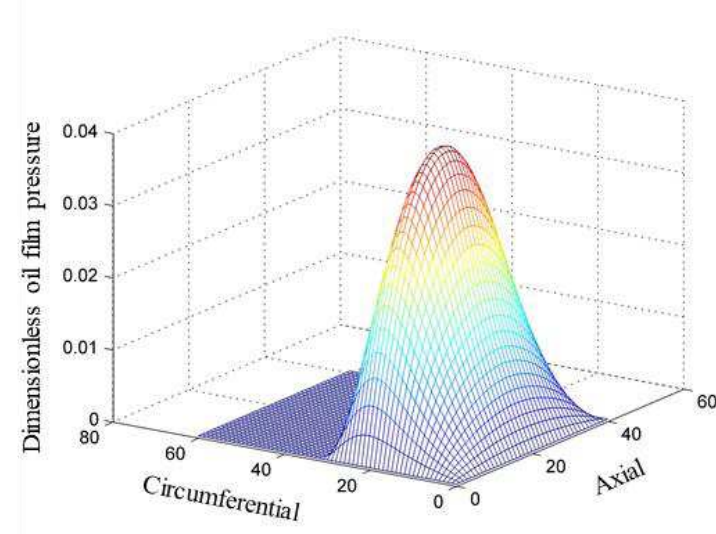

(b) $e=0.3$, ratio $=0.5$

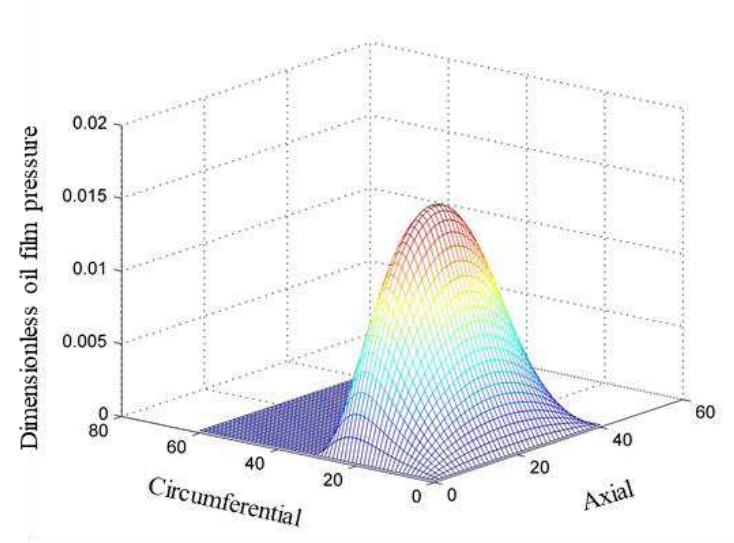

(d) $e=0.3$, ratio $=0.3$

Figure 6 Inner oil film pressure distribution.

The bearing capacity of the lubricating oil film lifts the journal and the floating ring to make it run, providing lubrication and damping effects, with less friction and vibration. According to the oil film pressure distribution calculated above, the bearing capacity of the oil film inside and outside of the floating ring bearing can be obtained from the vector sum of the oil film force of each micro-element area of the bearing working surface. According to the analysis of the working principle of the floating ring, the line of action of the bearing capacity of the inner oil film passes through the center of the journal and the center of the floating ring. The line of action of the bearing capacity of the outer oil film passes through the center line of the floating ring and the journal. 


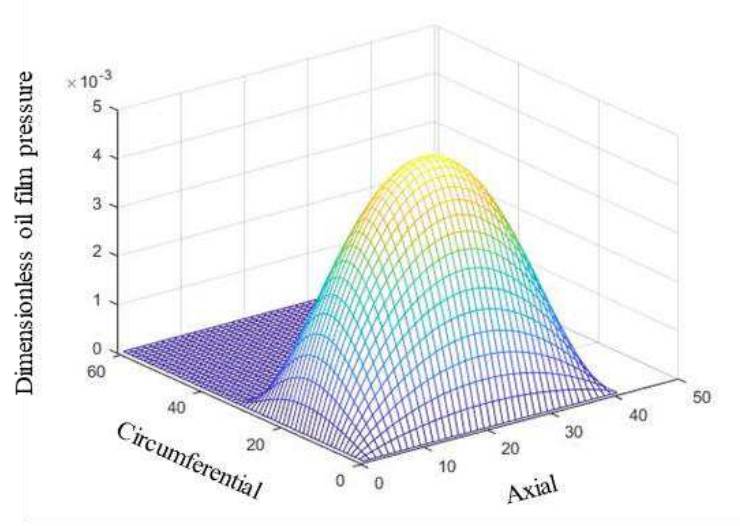

(a) $e=0.1$, ratio $=0.5$

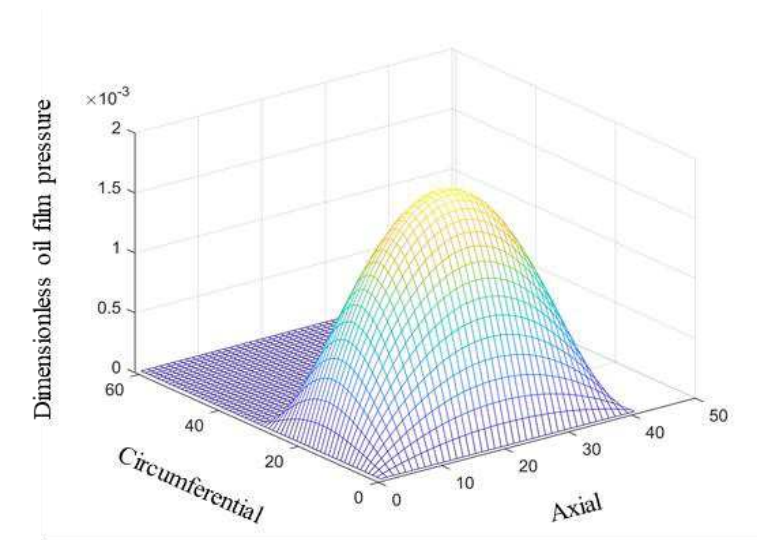

(c) $e=0.1$, ratio $=0.3$

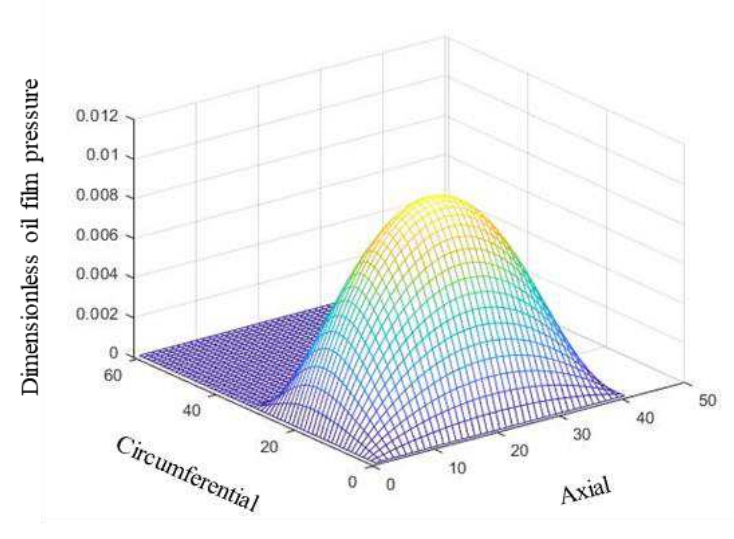

(b) $e=0.3$, ratio $=0.5$

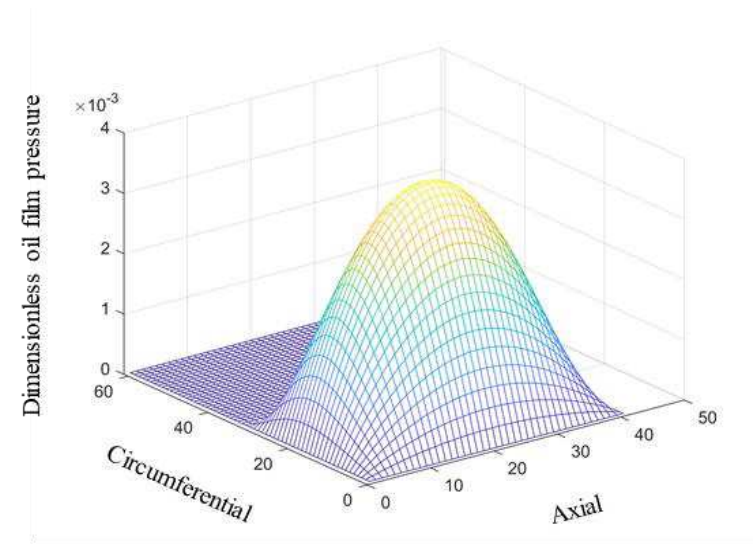

(d) $e=0.3$, ratio $=0.3$

Figure 7 Outer oil film pressure distribution.

After the dimensionless oil film pressure is calculated in the oil cavity, the dimensionless bearing capacity $W$ of the oil film can be obtained by integrating the oil film force on each micro-unit area of the bearing working surface. The calculation formula is expressed as

$$
\begin{aligned}
& W_{x}=\int_{-1}^{1} \int_{0}^{2 \pi} P \cos \varphi d \varphi d \lambda=\sum_{j=1}^{n} \sum_{i=1}^{m} P_{i, j} \cos \varphi_{i} \Delta \varphi \Delta \lambda \\
& W_{y}=\int_{-1}^{1} \int_{0}^{2 \pi} P \sin \varphi d \varphi d \lambda=\sum_{j=1}^{n} \sum_{i=1}^{m} P_{i, j} \sin \varphi_{i} \Delta \varphi \Delta \lambda
\end{aligned}
$$

The dimensionless oil film bearing capacity is expressed as

$$
W=\sqrt{W_{x}^{2}+W_{y}^{2}}
$$

At the same time, the deflection angle of the sliding bearing can be expressed as

$$
\theta=\operatorname{arctg} \frac{W_{x}}{W_{y}}
$$




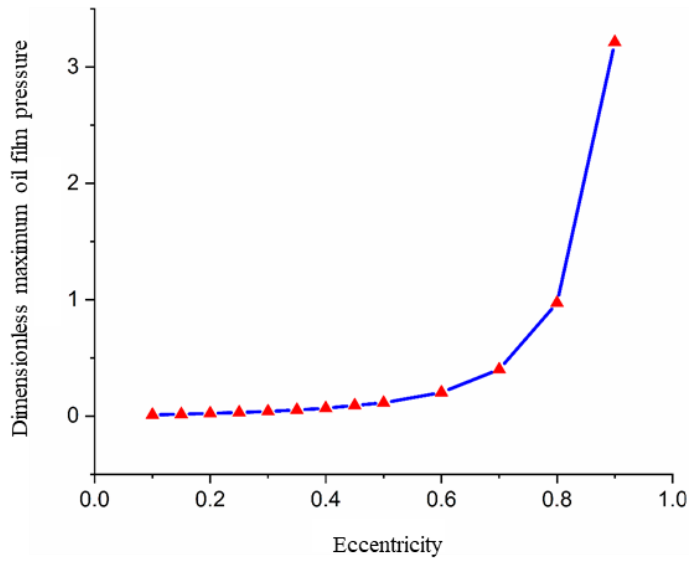

(a) Variation of the maximum oil film pressure with

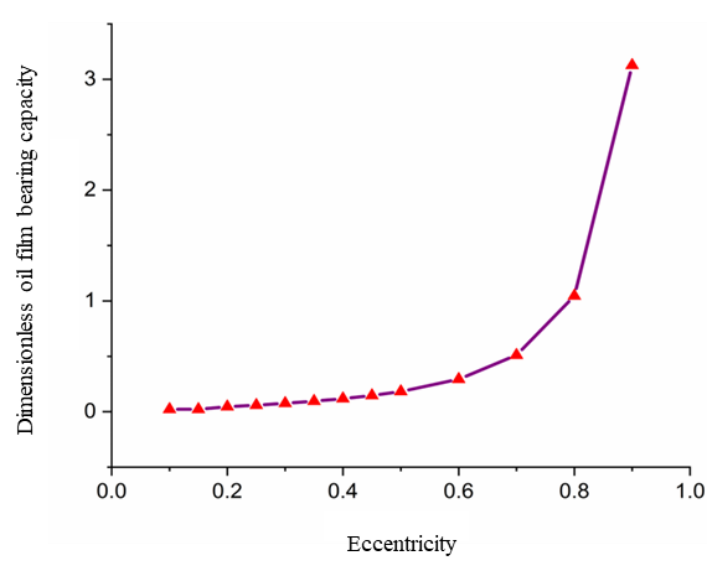

(b) Variation of the oil film bearing capacity with eccentricity. eccentricity.

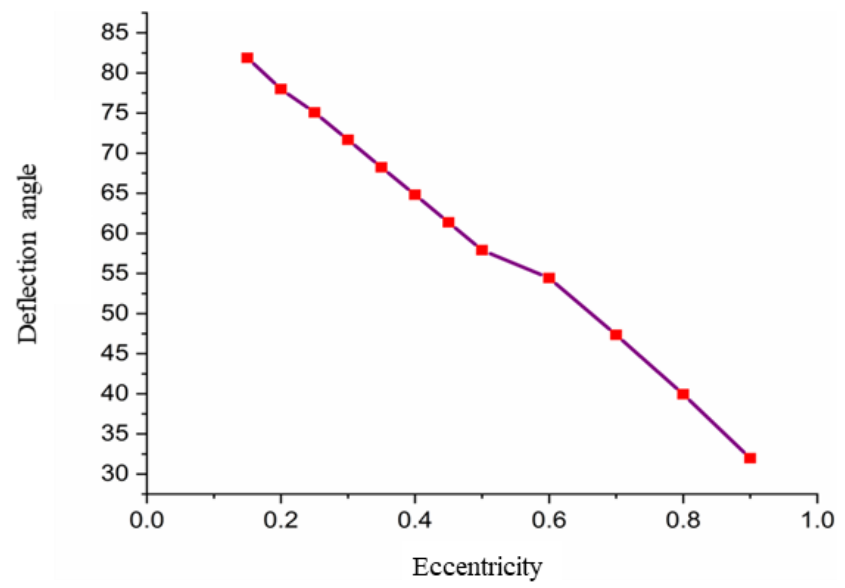

(c) Variation of deflection angle with eccentricity

Figure 8 Variations of dimensionless maximum oil film pressure, bearing capacity, and deflection angle with eccentricity.

Figure 8 shows the trend of the maximum oil film pressure, bearing capacity, and deflection angle with eccentricity. The maximum oil film pressure is located in the center of the wedge, which is the highest point in the oil film pressure distribution graph. It can be seen from Figure 8 (a) that the maximum oil film pressure is close to linear growth in the case of a small eccentricity. When the eccentricity exceeds 0.5 , the maximum oil film pressure increases sharply with the increase of eccentricity, showing a non-linear increase. From Figure 8 (b), it can be seen that the bearing capacity of the oil film increases with the increase of eccentricity. In the case of small eccentricity, the dimensionless bearing capacity of the oil film increases linearly. When the eccentricity exceeds 0.5 , the bearing capacity increases sharply and grows 
nonlinearly. It can be explained that the eccentricity is too large, the oil film squeezing effect is significantly enhanced, and it will show strong nonlinear characteristics. In the case of large eccentricity, the oil film may rupture, and the journal and the floating ring may be in direct contact at some locations. At this time, the bearing capacity can be regarded as infinite. It can be seen from Figure 8 (c) that the deflection angle decreases linearly with the increase of eccentricity.

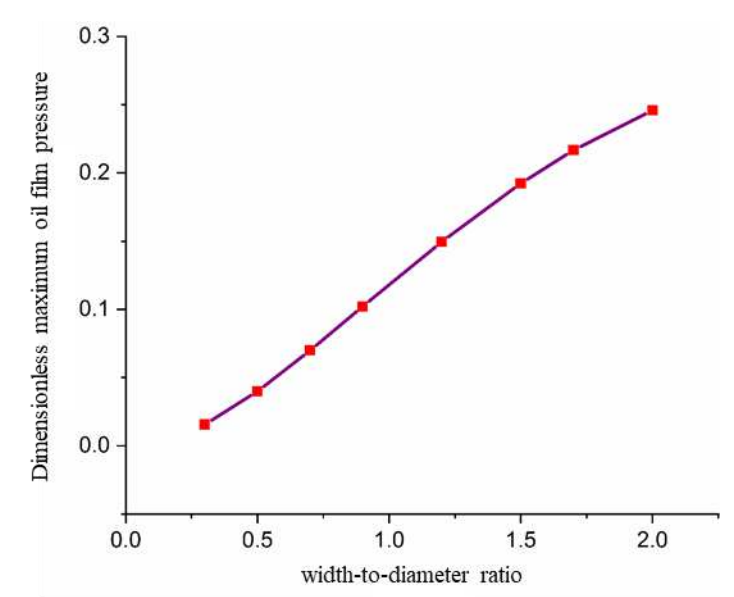

(a) Variation of maximum oil film pressure with the aspect ratio

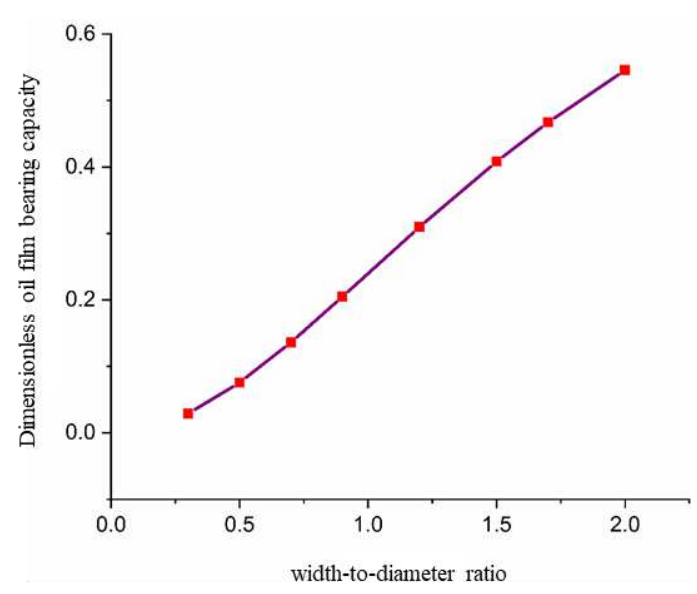

(b) Variation of the oil film bearing capacity with width to diameter ratio

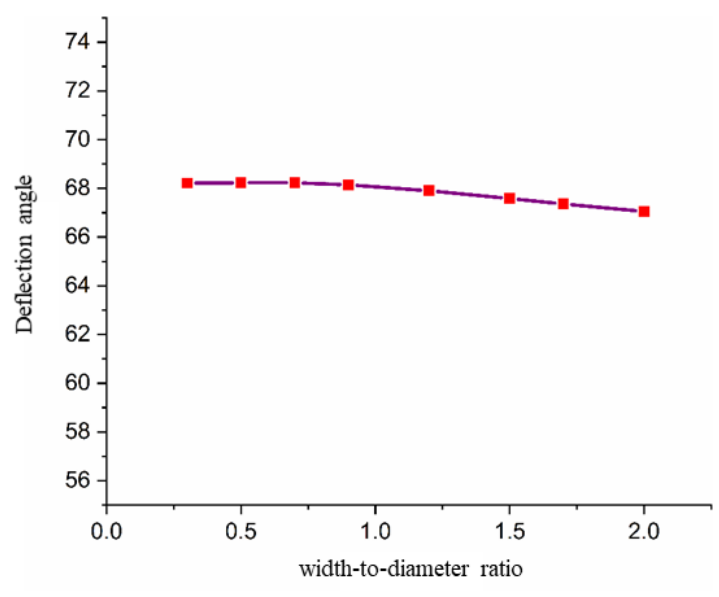

(c) Variation of deflection angle with width to diameter ratio

Figure 9 Variations of dimensionless maximum oil film pressure, bearing capacity, and deflection angle

It can be seen from Figure 9 (a) that the bearing capacity of the oil film increases linearly with the increase of the width-to-diameter ratio. The wider the bearing, the larger the bearing area, and the larger the bearing capacity. It can be seen from Figure 9 (b) that the maximum oil film pressure increases linearly with the increase of the width-to-diameter ratio. The wider the 
bearing, the greater the oil film pressure at the center of the wedge-shaped convergence zone. It can be seen from Figure 9 (c) that the deflection angle does not change with the increase of the width-to-diameter ratio, and the deflection angle is only related to the eccentricity.

\section{The numerical simulation of the floating ring-rotor system}

\subsection{Analysis of rotor stress}

The coupling of the oil film pressure of the floating ring bearing and the rotor stress is displayed as a moiré graph, as shown in Figure 10 below. The stress of the rotor section between the two floating rings is larger than that of the cantilever end. The stress of the shaft section in the central area is more concentrated. The oil film pressure at the bottom of the floating ring is relatively high.

The moiré diagram of the rotor stress distribution is shown in Figure 11. The beam section between the two floating ring bearings is a stress concentration area. The maximum stress in this area occurs at the supporting position of the floating ring 1 , which is $2.5 \times 10^{5} \mathrm{~Pa}$. The stress of floating ring 1 relative to the position of floating ring 2 is high, which is $1.6 \times 10^{5} \mathrm{~Pa}$. It means that the floating ring 1 will bear a more unbalanced load from the rotor-cantilever disk. At both ends of the rotating shaft, the stress at the outer cantilever end of the wheel distance is almost 0 , and the rotor stress from the cantilever distance to the floating ring segment gradually increases. 


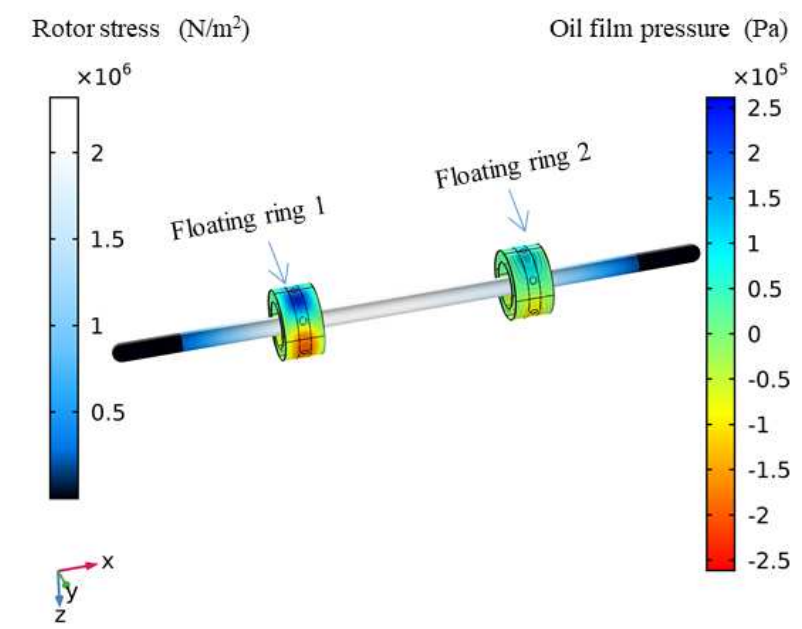

Figure 10 Moiré diagram of coupling distribution of inner and outer oil film pressure and rotor stress.

It can be seen from Figure 11 that the downward offset of the rotor in the floating ring 1 is greater than that of the floating ring 2 . At the same time, the downward deformation deflection of the outer cantilever end of the floating ring 1 is significantly greater than that of the outer cantilever end of the floating ring 2.

The change of the total reaction force of the floating ring bearing and the oil film support with time during the transient start of the rotor is shown in Figure 12. It can be seen that at the moment of starting, the total reaction force on the rotor increases rapidly from $0 \mathrm{~N}$ to $0.0055 \mathrm{~N}$. As time passes by, the amplitude begins to fluctuate continuously. The maximum peak value reaches $0.0065 \mathrm{~N}$ and stabilizes after $0.18 \mathrm{~s}$. The average value fluctuates slightly around 0.043 N.

The total reaction torque of the two floating ring bearings during the transient start of the rotor changes with time, as shown in Figure 13. The reaction torque from the damper fluid floating ring bearing generated the kinetic energy and the driven rotating floating ring consumed the kinetic energy. The total reaction torque changes with time in a quasi-periodic law with the fluctuation amplitude constantly attenuating. The maximum torque reaches 0.2 $(\mathrm{N} \cdot \mathrm{m})$, and then the torque amplitude decays continuously with time. After $0.18 \mathrm{~s}$, the torque decays to $0.06(\mathrm{~N} \cdot \mathrm{m})$, and then fluctuates slightly. 


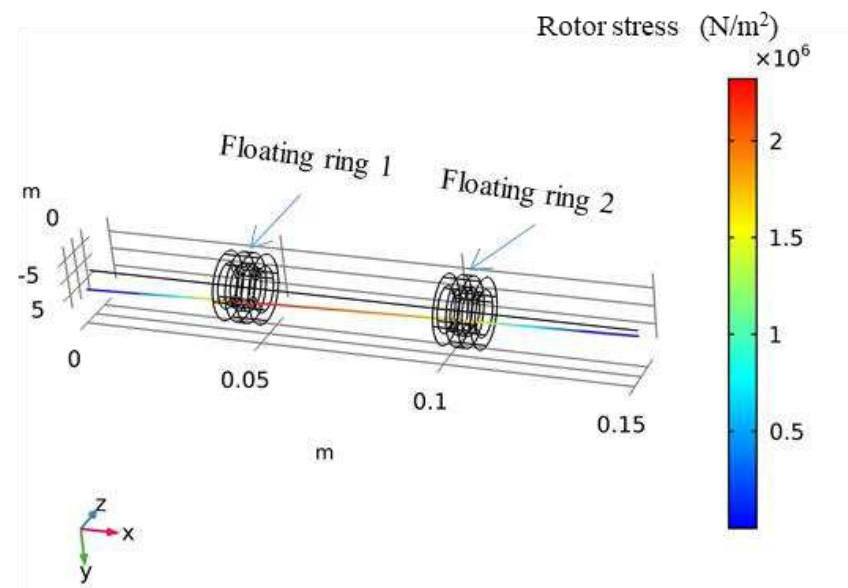

Figure 11 Moiré diagram of rotor stress distribution.

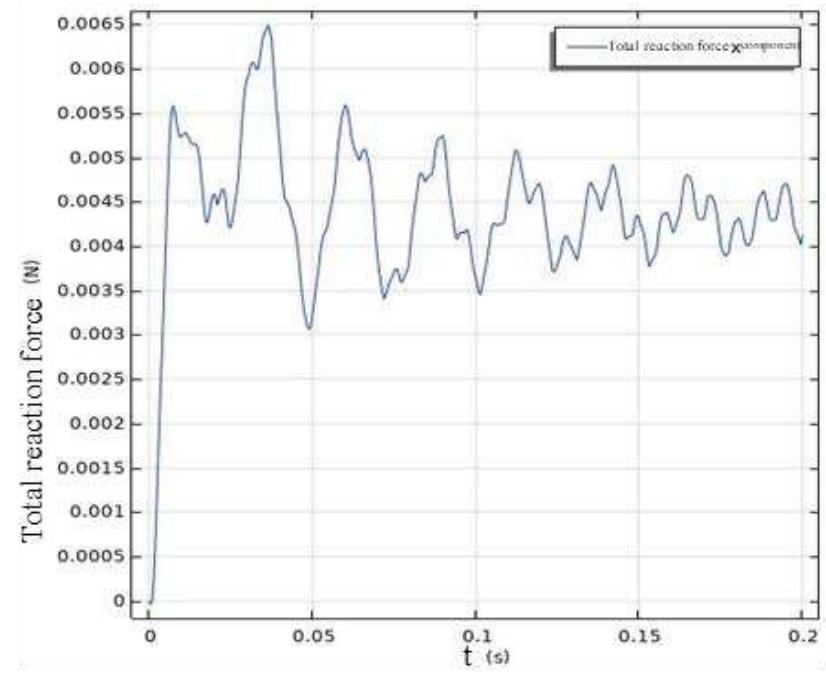

Figure 12 The total reaction force of the rotor changes with time.

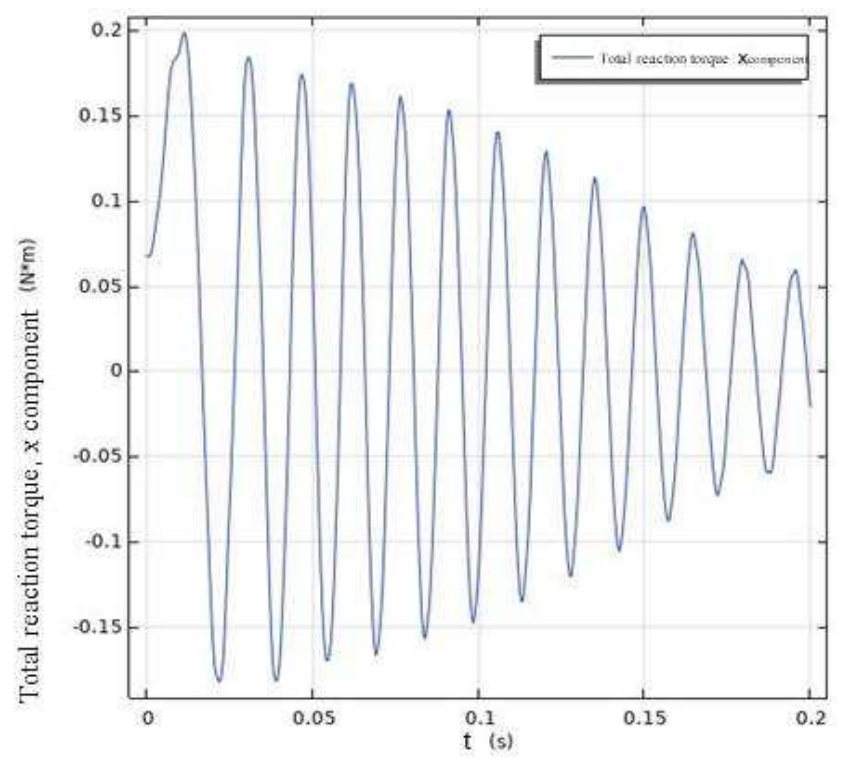

Figure 13 The total reaction torque of the rotor changes with time. 


\subsection{Analysis of oil film pressure distribution and fluid load}

The oil film pressure distribution of the inner and outer layers of the floating ring at the steady state of $8000 \mathrm{r} / \mathrm{min}$ is shown in Figure 14 . There are two obvious pressure concentration zones in each oil film. Blue represents the pressure divergence zone, namely negative pressure. Red represents the pressure convergence zone, namely positive pressure.

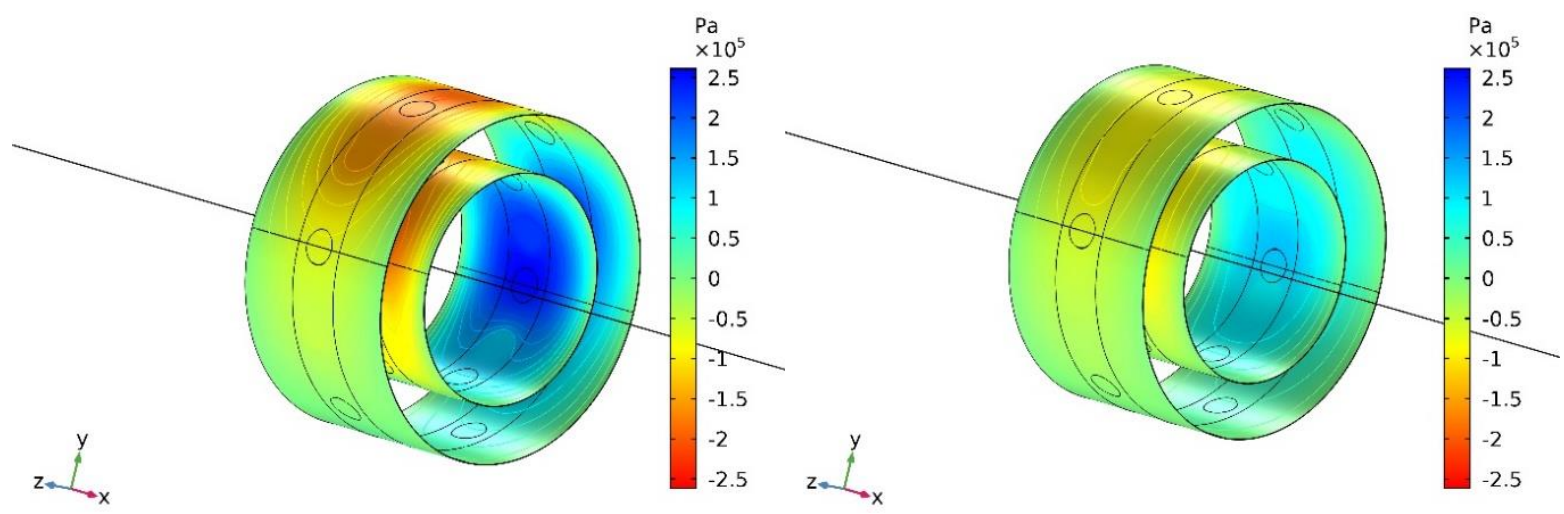

(a) Oil film pressure distribution of floating ring 1

(b) Oil film pressure distribution of floating ring 2

Figure 14 Oil film pressure distribution inside and outside the floating ring.

The maximum oil film pressure in the oil film squeeze convergence zone of floating ring 1 and floating ring 2 is $2.61 \times 10^{5} \mathrm{~Pa}$ and $1.5 \times 10^{5} \mathrm{~Pa}$, respectively. At the same time, the oil film pressure of floating ring 1 is greater than that of floating ring 2 , because the mass of wheel 1 is greater than that of wheel 2. Under high-speed rotating conditions and the same eccentricity, the unbalanced excitation generated by wheel 1 is higher than that of wheel 2 . Floating ring 1 bears a higher load from the rotor than floating ring 2 . In addition, the pressure of the inner oil film of the two floating rings is higher than that of the outer oil film. The inner oil film is directly squeezed by the journal, which needs to provide a larger bearing capacity.

It can be seen from the pressure contour that the maximum oil film pressure of the inner and outer oil films is located in the middle area of the floating ring. From the inside to the outside, the pressure decreases gradually, and the pressure at the outer end of the floating ring is the smallest. The simulation results of oil film pressure are consistent with the pressure distribution obtained by the numerical method in Chapter 2 . And in the area of the minimum oil film thickness, the positive pressure of the oil film transits to the negative pressure. The 
wedge-shaped convergence zone forms positive pressure, while the divergence zone forms negative pressure. In a clockwise direction, the pressure in the wedge-shaped zone gradually increases from 0 to the peak of positive pressure and then begins to decrease. It enters the divergence zone through the region of minimum oil film thickness, and the pressure gradually reaches the peak of negative pressure.

After calculating the oil film pressure distribution is calculated, the oil film pressure along the inner and outer surfaces of the floating ring is integrated. The fluid load components on the inner and outer surfaces of the floating ring in all directions are obtained, as shown in Figure 15. The following conclusions can be drawn from the figure: (1) The $y$-direction and $z$-direction components of the oil film fluid load inside and outside the floating ring are distributed in periodic sine waves. There is only a small fluctuation when the initial instantaneous load increases; (2) There is a phase difference between the inner oil film load and the outer oil film load. When the inner oil film load reaches the maximum value, the outer oil film load reaches the minimum value; (3) The fluid load on the floating ring 1 with larger bearing capacity and obvious oil film squeezing effect is greater than that on the lightly loaded floating ring 2 . After reaching the steady state, the peak values of the fluid load components in the $y$ and $\mathrm{z}$ directions received by the inner and outer membranes of the floating ring 1 are both $17 \mathrm{~N}$. The peak values of the load components received by the floating ring 2 in different directions are both $9 \mathrm{~N}$.

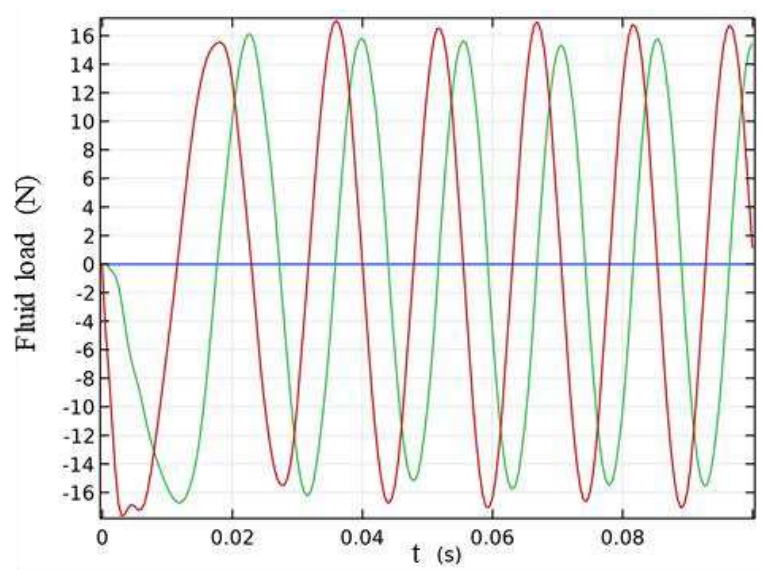

(a) The fluid load of the inner membrane of the floating

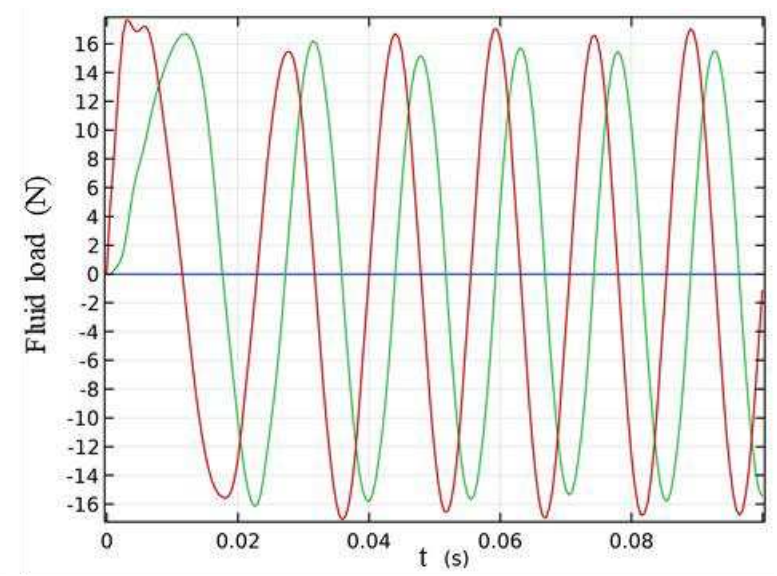

(b) The fluid load of the outer membrane of the floating 


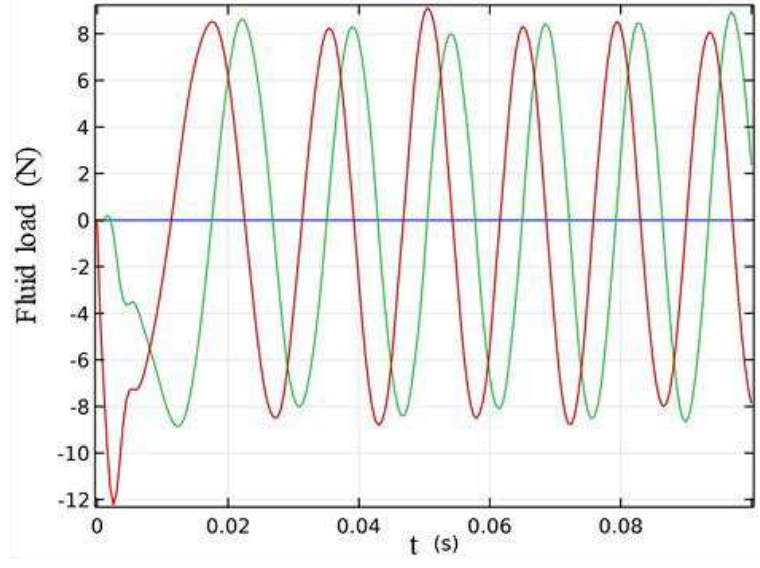

(c) The fluid load of the inner membrane of the floating

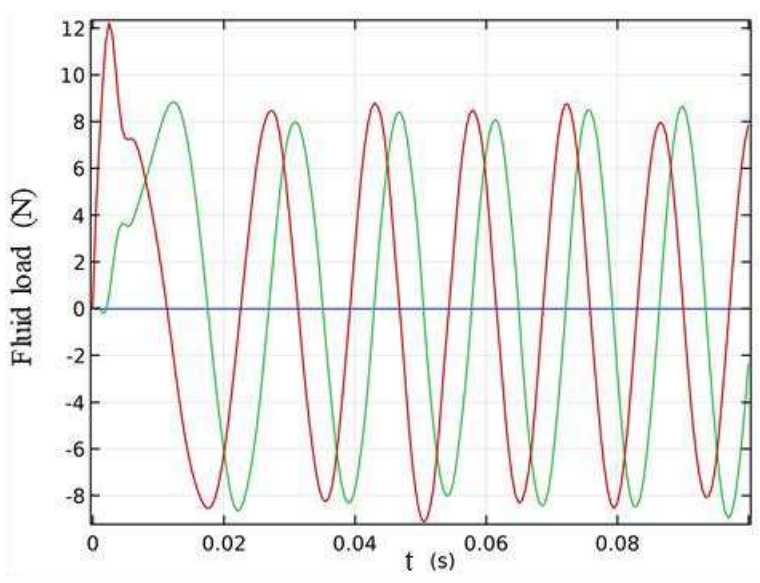

(d) The fluid load of the outer membrane of the floating

ring 2

— Fluid load on the ring, Intima, $\mathrm{X}$ component - Fluid load on the ring, Intima, $\mathrm{Y}$ component

— Fluid load on the ring, Intima, $\mathbf{Z}$ component

Figure 15 The relationship between the fluid load of the inner and outer layers of the oil film on the floating ring with time.

\subsection{Analysis of floating ring fluid torque and rotation speed}

When the system is started, the journal starts to accelerate and rotate. The rotation will drive the oil film in contact with the journal surface to start the shearing flow and finally drives the inner oil film to flow as a whole. At this time, there is a relative slippage between the fluidsolid contact wall of the inner oil film and the floating ring. There is no relative sliding motion at the fluid-structure interface between the outer membrane and the floating ring. Therefore, the relative sliding speed difference between the inner membrane and the outer membrane produces a viscous moment acting on the floating ring to make the floating ring start to rotate.

The fluid torque change on the floating ring is shown in Figure 16. The maximum fluid torque produced by the inner oil film is $0.04 \mathrm{~N} \cdot \mathrm{m}$, which continuously decreases to $0.016 \mathrm{~N} \cdot \mathrm{m}$ with time. The fluid torque of the outer oil film is initially 0 , and continues to increase to 0.016 $\mathrm{N} \cdot \mathrm{m}$ with time, which is a negative value. At this time, the inner and outer oil film fluid moments are in opposite directions. The total moment received decreases from $0.04 \mathrm{~N} \cdot \mathrm{m}$ to 0 with time, and the force of the floating ring reaches a balanced state.

The speed change of the floating ring is shown in Figure 17. Due to the net torque on the 
ring, it starts to accelerate axially, and the speed continues to increase. The subsequent rotation of the ring reduces the relative slip speed of the ring and the oil film. This result will lead to a decrease of the viscous force from the inner membrane and an increase of the viscous force from the outer membrane. The direction of the outer membrane torque and the inner membrane torque is opposite and cancels each other out. It can also be seen from the slope change of the ring velocity curve in Figure 17 that the net angular acceleration of the ring continuously decreases with the acceleration of the ring. Eventually, the floating ring will reach a stable rotation. When the torque of the outer membrane is equal and opposite, the net angular acceleration of the ring becomes zero. The force of the floating ring reaches a balanced state, and the fluid torque drops to 0 . Then, the floating ring will keep rotating at this speed.

Under the sub-working condition of $8000 \mathrm{r} / \mathrm{min}$, the floating ring 1 bears a greater load and the oil film squeezing effect is greater. As shown in Figure 17, the minimum oil film thickness is smaller and the viscous moment generated on the floating ring is greater, so the floating ring speed of ring 1 is higher than that of floating ring 2 . The maximum angular velocity of floating ring 1 is $450 \mathrm{r} / \mathrm{min}$, the maximum rotating speed of floating ring 2 is $430 \mathrm{r} / \mathrm{min}$, and the rotating speed of floating ring 1 is slightly larger. The maximum angular acceleration of floating ring 1 is $2.5 \times 10^{4}\left(\mathrm{r} / \mathrm{min}^{2}\right)$. Under this working condition, the rotating speed ratio of the floating ring to the rotor is $5.6 \%$. Compared with the rotor speed, the floating ring only rotates in the oil chamber at a very small speed. 


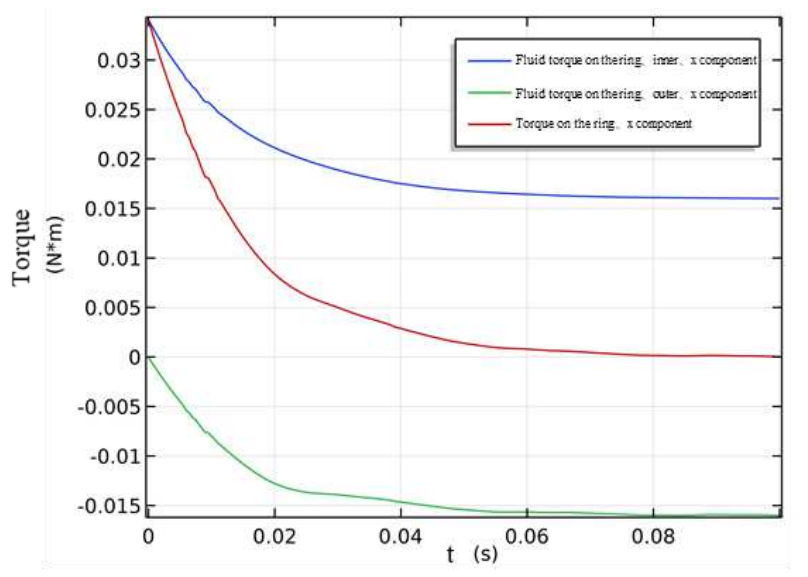

Figure 16 The torque of floating ring 1 changes with time.

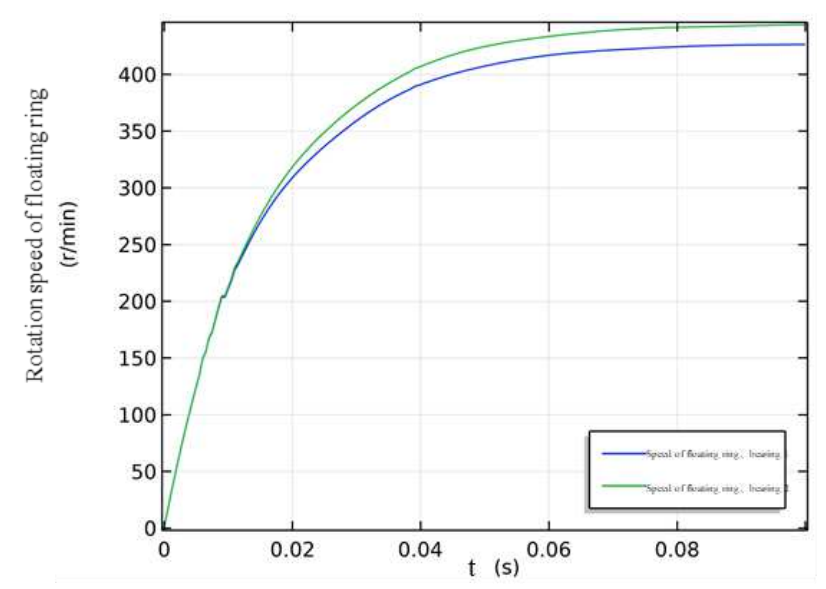

Figure 17 The speed of the floating ring changes with time.

\subsection{Analysis of rotor and floating ring trajectory}

The axis motion track of the rotor in the ring is shown in Figure 18, which fully shows the adjusting effect of floating ring squeeze film damper on the rotor vibration. In the initial transient stage, the rotor is subjected to the oil film force and oil film damping provided by the floating ring damper, and the vibration is continuously reduced. After a process of rapid amplitude convergence, the rotor finally reaches the equilibrium state, and a small amplitude convergence is performed around the equilibrium point of the ring. The trajectory of floating ring 2 converges faster than that of floating ring 1, but the amplitude of the floating ring 2 in the final equilibrium state is significantly greater than that of floating ring 1. 


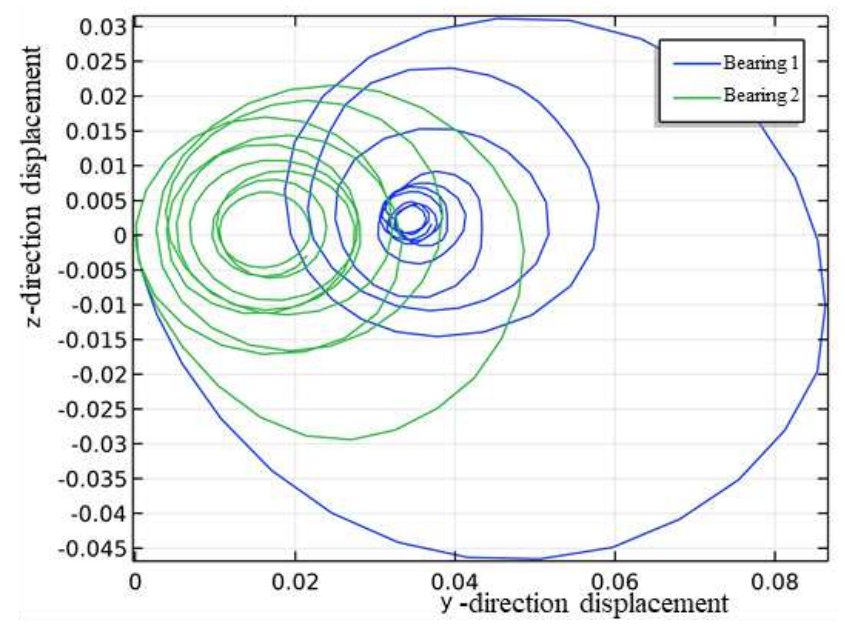

Figure 18 The rotor axis trajectory changes with time.

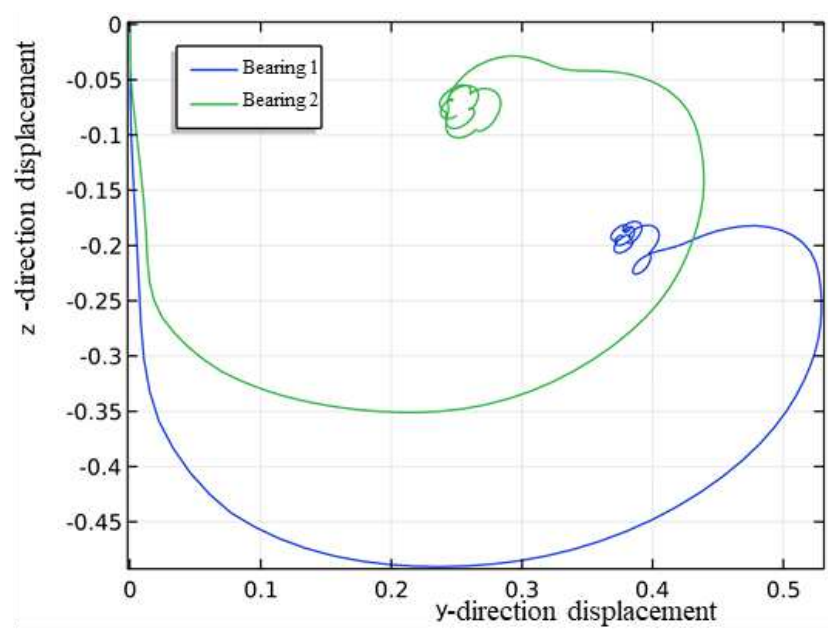

Figure 19 Floating ring center trajectory changes with time.

The moving track of the floating ring is shown in Figure 19. In the initial transient phase, when the rotation speed is small, the oil film force is also small, and the floating ring sinks due to the gravity of the rotor and the turbine disk. The maximum sinking amount of floating ring 1 is $0.5 \mathrm{~mm}$, and the maximum sinking amount of floating ring 2 is $0.35 \mathrm{~mm}$. As the rotor speed increases, the oil film pressure increases, the oil film bearing capacity also increases, and the floating ring starts to float. This process is basically synchronized with the convergence process of the rotor shaft trajectory and finally reaches a balanced state. In the balanced state, the floating ring 1 moves downward by $0.2 \mathrm{~mm}$, and the floating ring 2 moves downward by $0.075 \mathrm{~mm}$. The amplitude vibration is small near the equilibrium point. 


\subsection{Oil film thickness and oil film flow analysis}

The flow rate of the oil hole channel in the squeeze zone of floating ring 1 and floating ring 2 is shown in Figure 20. The flow rate is defined as "the mass of fluid passing through the oil hole per unit time". In the very short transient start-up process of the system, the quasiperiodical behavior of the flow can be seen. When the system reaches a steady state, the change of the flow rate is periodic. In a cycle, the flow rate changes from positive to negative. When the flow rate is positive, it means that channel 1 is located in the positive pressure zone, and the oil film is squeezed out. This effect squeezes the lubricating oil in the inner cavity from channel 1 to the outer cavity. When the flow rate is negative, it means that channel 1 is in the negative pressure zone. The lubricating oil flows from the outer oil cavity to the inner oil cavity, so as to keep the balance of the lubricating oil flow in the oil cavity. At the same time, it is noticed from the figure that within one cycle, the positive flow rate has a peak with a larger value while the negative flow rate has two valleys with a smaller value. From Figure 14, it can be found that in the whole oil film pressure distribution, the area of the positive pressure convergence zone is small and the pressure is large, which includes only one channel, and the negative pressure zone contains two channels. Channel 1 needs to squeeze out more oil per unit time after passing through the positive pressure zone, so the flow rate value is larger and there is only one peak value; when channel 1 passes through the two-channel positions in the negative pressure zone one after another, the lubricating oil will flow back, which will cause two troughs. And it can be observed that when the system reaches a steady state, the channel flow rate fluctuation range of floating ring 1 is significantly higher than that of floating ring 2 . The maximum flow rate of floating ring 1 is $5 \mathrm{~kg} / \mathrm{s}$, and the maximum flow rate of floating ring 2 is $2 \mathrm{~kg} / \mathrm{s}$, which shows that the squeezing effect of floating ring 1 is greater. 


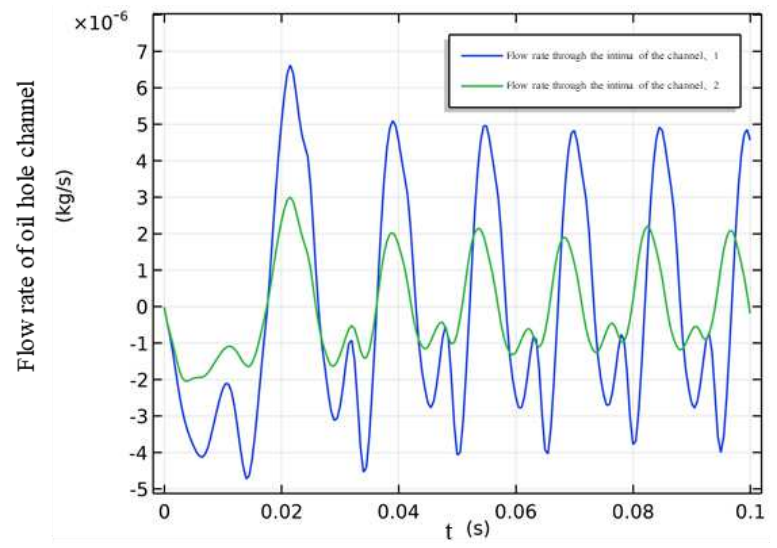

Figure 20 Channel 1 is the process flow rate changes with time.

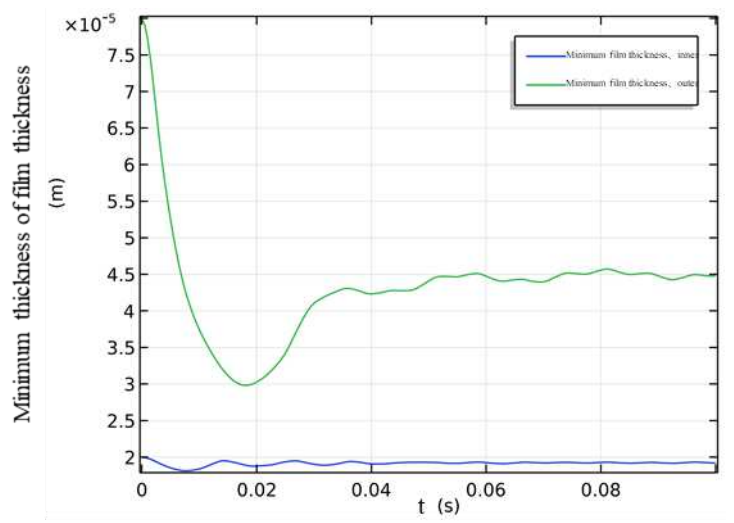

(a) Minimum oil film thickness of floating ring 1

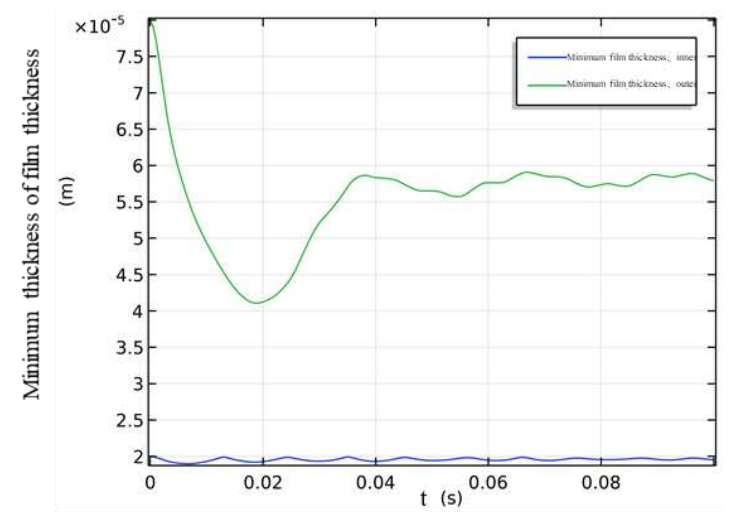

(b) Minimum oil film thickness of floating ring 2

Figure 21 The minimum oil film thickness varies with time.

The change process of the minimum oil film thickness with time is shown in Figure 21. In the model setting, the bearing inner clearance is $0.02 \mathrm{~mm}$, and the bearing outer clearance is $0.08 \mathrm{~mm}$, which is the initial oil film thickness. From the analysis results of the above figure, it can be seen that the minimum oil film thickness of the inner film of the floating ring bearing 1 fluctuates very little due to the limitation of the initial gap; the minimum oil film thickness of the outer film undergoes a significant reduction within 0.02 seconds of the initial transient stage. The thickness drops from $0.08 \mathrm{~mm}$ to $0.03 \mathrm{~mm}$, then rises to $0.045 \mathrm{~mm}$ within $0.02-0.05 \mathrm{~s}$, and then reaches a steady state. The change rule of the minimum oil film thickness of bearing 2 is similar to that of bearing 1 , but the fluctuation range of the minimum oil film thickness of the outer film is relatively small. The initial transient state drops from $0.08 \mathrm{~mm}$ to $0.041 \mathrm{~mm}$ and then returns to $0.058 \mathrm{~mm}$, reaching a steady state. The minimum oil film thickness of bearing 2 is greater than that of bearing 1 . Within 0.02 seconds of the initial transient phase, the minimum 
oil film thickness of the inner oil film decreases significantly, almost approaching zero. Due to the existence of oil holes on the floating ring, after squeezing out too much oil, the thickness of the oil film will continue to decrease and the pressure of the oil film will increase. This result may cause the oil film to rupture somewhere in the squeeze zone, and the journal and the floating ring are in direct contact and friction. At the same time, a strong nonlinear disturbance is generated to the rotor system, resulting in increased vibration; and the wear of the floating ring will shorten its service life, which is a problem worthy of attention.

\section{Analysis of dry and wet modes of ring squeeze film damper}

The modal parameters of the structure in the fluid are different from the modal parameters of the structure in the air. The ring squeeze film damper is suspended in the oil cavity when it works, so when its dynamic characteristics are studied, it is necessary to consider the influence of the surrounding fluid on it. The main manifestation is that the fluid is viscous and may be attached to the surface of the structure. The fluid will move with the movement of the structure, the energy of the structure will be consumed, the additional mass of the structure will be produced, and the damping characteristics of the structure will also be changed.

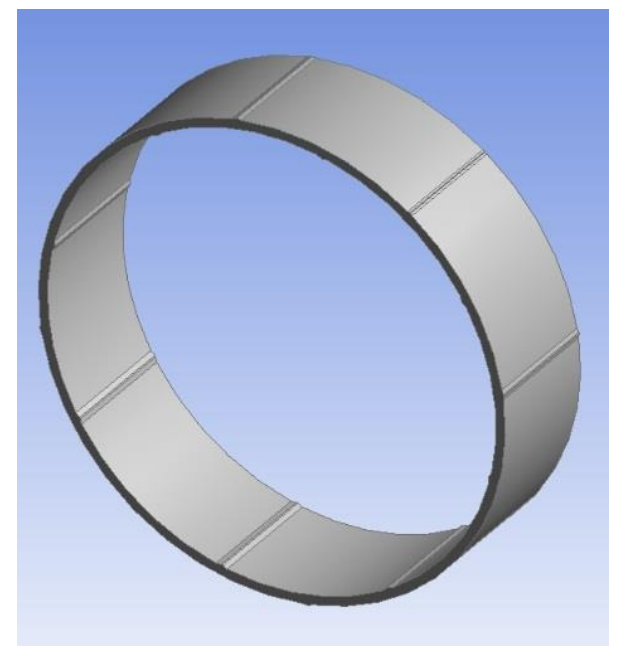

(a) three-dimensional model of elastic ring

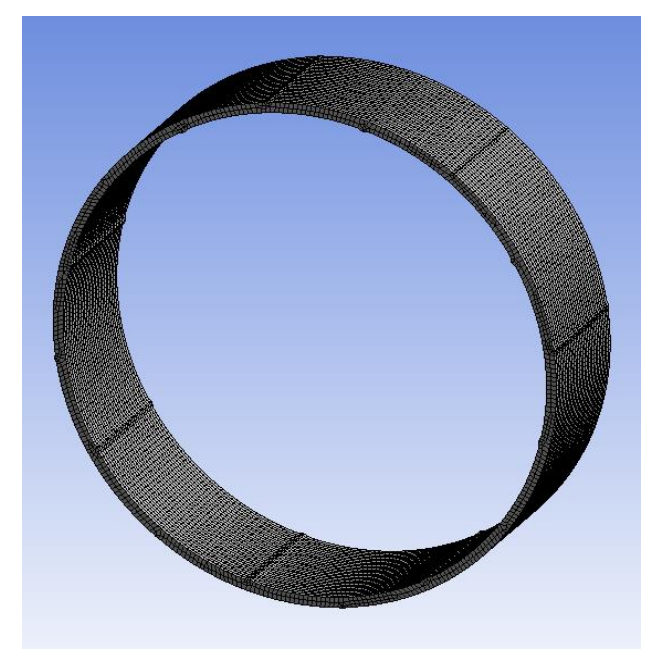

(b) Meshing result

Figure 22 The three-dimensional model of the elastic ring of the boss and the finite element meshing results.

In the dynamic equation of the structure, the mass matrix and the damping matrix will change, and the natural frequency and mode shape in the solution result will also change accordingly. The three-dimensional model of the elastic ring is shown in Figure 22. 


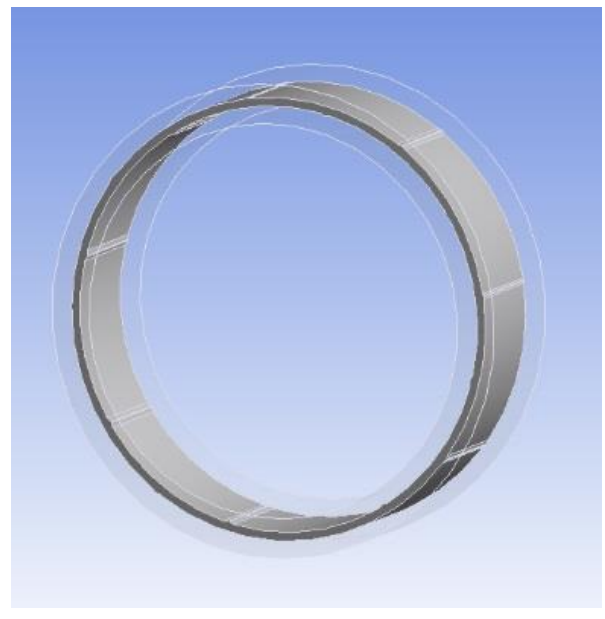

(a) Elastic ring immersion model

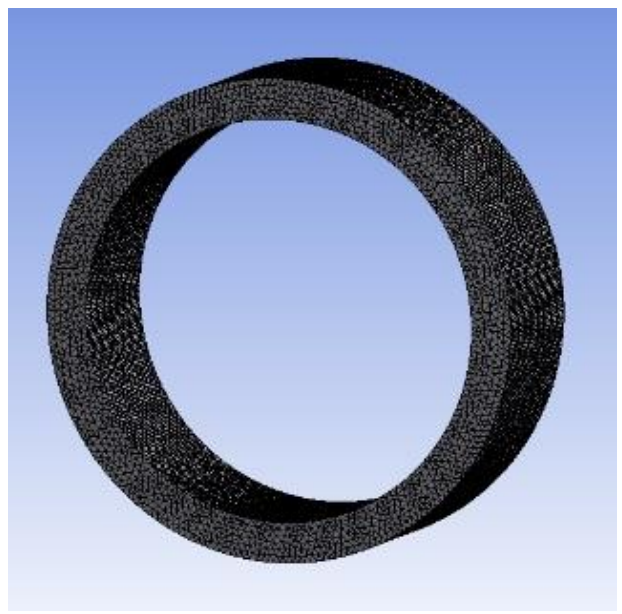

(b) Fluid-structure coupling meshing results

Figure 23 Elastic circulation fluid-solid coupling model and meshing results.

A three-dimensional geometric model of the fluid domain-solid domain surrounding the elastic ring is established, as shown in Figure 23(a). The fluid domain material is preset to the solid material properties consistent with the elastic ring, and the fluid domain material properties are modified. The fluid density adopts the parameters of ordinary lubricating oil which is set to $1170 \mathrm{~kg} / \mathrm{m}^{3}$, and the sound velocity in the lubricating oil is set to $1600 \mathrm{~m} / \mathrm{s}$. In actual working conditions, the elastic ring is suspended in the oil cavity and is in a free state, so there is no need to add loads and constraints. Before the grid is divided, the fluid domain and the solid structure are combined into a whole, and the grid is divided at the same time to prevent grid interference on the fluid-structure coupling interface.

The calculation results of the first, third, and fifth order modes are shown in Table 3, and the corresponding modal diagrams are shown in Figure 24.

The relative error of the defined dry and wet mode is expressed as

$$
\varphi_{d}=\left|\frac{f_{s}-f_{w}}{f_{s}}\right| \times 100 \%
$$

where $f_{\mathrm{s}}$ is the natural frequency result obtained by dry mode calculation, and $f_{w}$ is the natural frequency result obtained by wet mode calculation. 

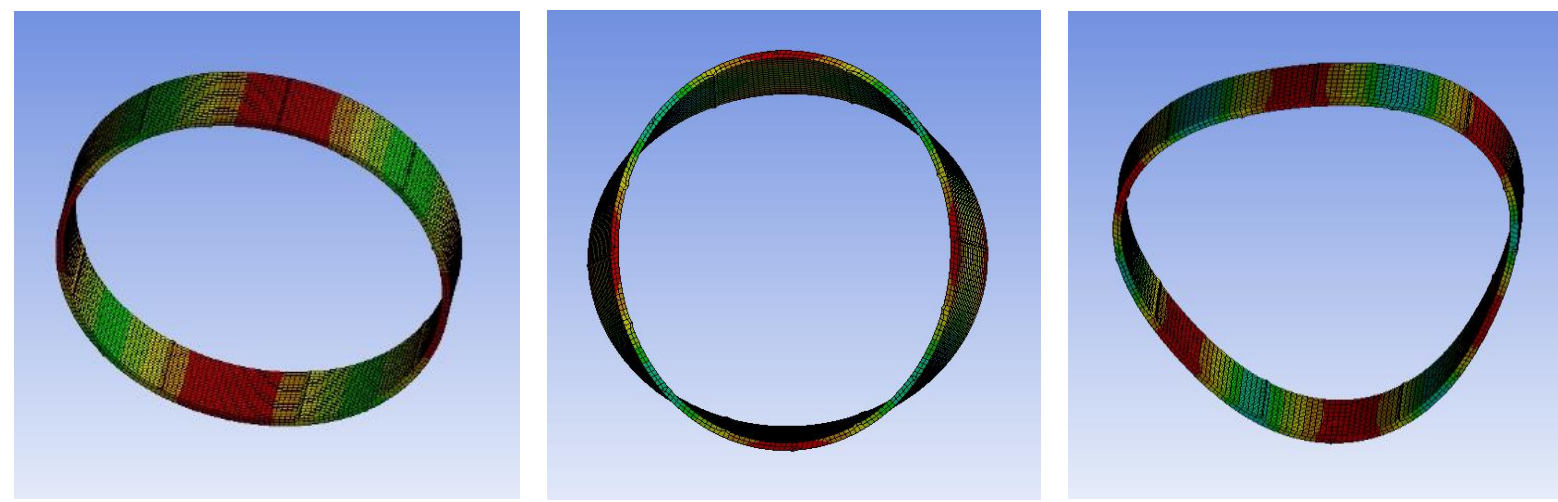

Figure 24 The first, third, and fifth order vibration modes of the elastic ring wet mode.

Table 3 Natural frequency comparison of elastic ring dry and wet mode.

\begin{tabular}{cccc}
\hline Natural frequency & First order frequency & Third order frequency & Fifth order frequency \\
\hline Dry mode calculation results & $915.78 \mathrm{~Hz}$ & $2024.1 \mathrm{~Hz}$ & $2592.4 \mathrm{~Hz}$ \\
Wet mode calculation result & $788.75 \mathrm{~Hz}$ & $1953.6 \mathrm{~Hz}$ & $2199.7 \mathrm{~Hz}$ \\
Natural frequency drop rate & $13.87 \%$ & $3.48 \%$ & $15.15 \%$ \\
in wet mode & & & \\
\hline
\end{tabular}

It can be seen from the calculation results that the vibration modes of the elastic ring are basically the same in the wet and dry modes. The first order mode is the radial tensile deformation of the ring, the third order mode is the axial bending and eversion deformation, and the fifth order mode is the triangular deformation. The first order natural frequency in the dry state is $915.78 \mathrm{~Hz}$, and the first order natural frequency in the wet mode is $788.75 \mathrm{~Hz}$. The results show that the additional mass of lubricating oil fluid has a great influence on the ring structure quality matrix, which makes the natural frequency of the ring wet mode lower than that of the dry mode. The first and fifth orders are reduced by $13.87 \%$ and $15.15 \%$, respectively, and the third order is reduced relatively small, at $3.48 \%$.

The frequency of the first and fifth order modes has a large drop. The reason is that the first order mode is radially stretched, and the fifth order mode also vibrates in a triangular shape in the radial direction. The two modes are greatly affected by the radial fluid, but the third order mode of vibration is axially bent, which is less affected by the radial oil film.

\section{Conclusion}

In this paper, the ring squeeze film damper commonly used in the aero-engine rotor support 
system is regarded as the research object. Based on theoretical analysis, numerical calculation and finite element simulation methods, the oil film pressure distribution, fluid-structure coupling dynamic characteristics, and elastic ring support stiffness of the ring squeeze film damper-rotor system are analyzed. The main research contents and conclusions are as follows:

(1) The Reynolds equation of the classical lubrication theory is derived according to the hydrodynamic lubrication theory and the working principle of the floating ring squeeze film damper. The finite difference method is used to solve the oil film pressure distribution of the inner and outer layers of the floating ring.

(2) Based on the finite element difference method, the inner and outer oil film pressure distribution of the floating ring is solved: (1)The maximum oil film pressure keeps increasing with the increase of eccentricity, and it increases linearly with small eccentricity and increases non-linearly with large eccentricity exceeding 0.5 . (2) The bearing capacity of the oil film increases with the increase of eccentricity. In the case of small eccentricity, the dimensionless bearing capacity of the oil film increases linearly. After the eccentricity exceeds 0.5 , the bearing capacity increases sharply, showing a non-linear growth. The squeeze effect of the oil film is significantly enhanced, showing strong nonlinear characteristics. (3) The deflection angle decreases linearly with the increase of eccentricity. With the increase of the aspect ratio, the maximum oil film pressure increases linearly. The bearing capacity of the oil film also increases linearly with the increase of the aspect ratio. The deflection angle has nothing to do with the change of the aspect ratio.

(3) The transient simulation results reveal the distribution of oil film pressure, the characteristics of floating ring motion and its reduction vibration mechanism. In the balanced state, compared with the rotor speed, the floating ring rotates in the oil cavity at a very small speed. The results of the shaft trajectory and floating ring trajectory changes during the rotor start-up speed-up process show that the ring squeeze film damper has a significant effect on regulating rotor vibration, and the rotor shaft trajectory quickly converges to a balanced state and then whirls slightly in the ring.

(4) The natural frequency and mode shape of the ring squeeze film damper in the dry state 
and the oil-filled state of the oil cavity are studied by the fluid-structure coupling method, and the following conclusions are obtained: the elastic ring has similar dry and wet modes, and the lubricating oil makes the natural frequency of the elastic ring in the wet mode is lower than that in the dry mode. The first and fifth orders are reduced by $13.87 \%$ and $15.15 \%$ respectively, and the third order is reduced by $3.48 \%$.

\section{Credit authorship contribution statement}

Mingming Shi: Conceptualization, Methodology, Validation, Data analysis, Investigation, Writing original draft.

Yongfeng Yang: Writing-review \& editing, Supervision, Funding acquisition.

Jianjun Wang: Data curation, Validation, Formal analysis.

Wangqun Deng: Validation, Formal analysis, Project administration.

Desheng Zhang: Formal analysis, Project administration.

\section{Declaration of competing interest}

The authors declare that data generated during this paper are available from the corresponding author (Email: yyf@nwpu.edu.cn) on reasonable request. Authors would like to declare on behalf of my co-authors that the work described was original research that has not been published previously, and not under consideration for publication elsewhere, in whole or in part. No conflict of interest exits in the submission of this manuscript, and manuscript is approved by all authors for publication. All the authors listed have approved the manuscript that is enclosed.

This research was funded by National Natural Science Foundation of China, grant number 11972295, 12172289, and the Key Laboratory of Aero-engine Vibration Technology, Aero Engine Corporation of China, grant number KY-1003-2020-0037, KY-52-2018-0020.

\section{Reference}

[1] H.R. Heidari, P. Safarpour, Design and modeling of a novel active squeeze film damper, Mech. Mach. Theory. 105 (2016).

[2] J. Vance, F. Zeidan, B. Murphy, Machinery Vibration and Rotordynamics, 2010.

[3] S. Zhao, X. Ren, W. Deng, K. Lu, Y. Yang, C. Fu, A transient characteristic-based balancing 
method of rotor system without trail weights, Mech. Syst. Signal Process. 148 (2021). https://doi.org/10.1016/j.ymssp.2020.107117.

[4] H. lun Zhou, G. huo Luo, G. Chen, F. Wang, Analysis of the nonlinear dynamic response of a rotor supported on ball bearings with floating-ring squeeze film dampers, Mech. Mach. Theory. 59 (2013).

[5] B. Han, Q. Ding, Forced responses analysis of a rotor system with squeeze film damper during flight maneuvers using finite element method, Mech. Mach. Theory. 122 (2018) 233-251.

[6] H. Guo, Z.M. Zhang, S.L. Zhang, S.Q. Cen, Multi stable regions of hydrodynamic floating ring journal bearing-rotor system, Zhendong Yu Chongji/Journal Vib. Shock. 35 (2016).

[7] K. Gjika, L. San Andrés, G.D. Larue, Nonlinear dynamic behavior of turbocharger rotorbearing systems with hydrodynamic oil film and squeeze film damper in series: Prediction and experiment, J. Comput. Nonlinear Dyn. 5 (2010) 1-8.

[8] L. Ma, J. hong Zhang, J. wei Lin, J. Wang, X. Lu, Dynamic characteristics analysis of a misaligned rotor-bearing system with squeeze film dampers, J. Zhejiang Univ. Sci. A. 17 (2016).

[9] L. San Andres, Damping and inertia coefficients for two open ends squeeze film dampers with a central groove: Measurements and predictions, J. Eng. Gas Turbines Power. 134 (2012).

[10]G. Adiletta, Bifurcating behaviour of a rotor on two-lobe wave squeeze film damper, Tribol. Int. 92 (2015).

[11]L.S. Andrés, Liquid cavitation in fluid film bearings, Mod. Hydrodyn. Lubr. Theory (Lecure Notes). (2009).

[12]P. Ferfecki, J. Zapoměl, J. Kozánek, Analysis of the vibration attenuation of rotors supported by magnetorheological squeeze film dampers as a multiphysical finite element problem, Adv. Eng. Softw. 104 (2017).

[13]C. Xing, Analysis of the characteristics of a squeeze film damper by three-dimensional Navier-Stokes equations: A numerical approach and experimental validation, ProQuest Diss. Theses. (2009).

[14]Z.C. Liu, M.F. Liao, P.H. Cong, Y. Li, J. Wang, S.J. Wang, Experimental investigation for effects of static eccentricity on vibration attenuating characteristics of squeeze film damper, Tuijin Jishu/Journal Propuls. Technol. 37 (2016).

[15]Z.C. Liu, M.F. Liao, P.H. Cong, J. Wang, S.J. Wang, B. Shi, Y. Li, Design method of squeeze film damper for aero-engine rotors, Hangkong Dongli Xuebao/Journal Aerosp. Power. 30 (2015). 
[16]H.L. Zhou, G.H. Luo, G. Chen, H.T. Tian, Two dynamic models of dual clearance squeeze film damper and their verification, Tribol. Int. 66 (2013).

[17]H.L. Zhou, G.Q. Feng, G.H. Luo, Y.T. Ai, D. Sun, The dynamic characteristics of a rotor supported on ball bearings with different floating ring squeeze film dampers, Mech. Mach. Theory. 80 (2014).

[18]H. Zhou, M. Zhang, X. Cheng, Z. Tang, P. Cao, Effects of Oil Supply Conditions on Equivalent Damping and Circumferential Position Damping of Squeeze Film Damper, Jixie Gongcheng Xuebao/Journal Mech. Eng. 54

[19]S. Jäger, S. Vogel, Validation of a squeeze-film-damper test rig by using multibody cosimulation, Multibody Syst. Dyn. 34 (2015).

[20]J. Cao, T. Dimond, P. Allaire, Numerical analysis of flexible rotor with nonlinear bearings and squeeze film dampers, in: ASME Int. Mech. Eng. Congr. Expo. Proc.

[21]Z.S. Liu, M. Zhang, F.C. Xu, N. Xu, Test for an open-ended finite length cylindrical squeeze film damper, Zhendong Yu Chongji/Journal Vib. Shock. 31 (2012).

[22]W. Zhang, Q. Ding, Elastic ring deformation and pedestal contact status analysis of elastic ring squeeze film damper, J. Sound Vib. 346 (2015).

[23]S. Hamzehlouia, K. Behdinan, Squeeze Film Dampers Executing Small Amplitude Circular-Centered Orbits in High-Speed Turbomachinery, Int. J. Aerosp. Eng. 2016 (2016).

[24]J. Zapoměl, P. Ferfecki, J. Kozánek, Modelling of magnetorheological squeeze film dampers for vibration suppression of rigid rotors, Int. J. Mech. Sci. 127 (2017).

[25]G. Adiletta, An insight into the dynamics of a rigid rotor on two-lobe wave squeeze film damper, Tribol. Int. 116 (2017).

[26]L.S. Andres, B. Koo, S.H. Jeung, Experimental Force Coefficients for Two Sealed Ends Squeeze Film Dampers (Piston Rings and O-Rings): An Assessment of Their Similarities and Differences, J. Eng. Gas Turbines Power. 141 (2019).

[27]H. Chen, L. Hou, Y. Chen, R. Yang, Dynamic characteristics of flexible rotor with squeeze film damper excited by two frequencies, Nonlinear Dyn. 87 (2017).

[28] G.J. Lee, J. Kim, T. Steen, Application of Computational Fluid Dynamics Simulation to Squeeze Film Damper Analysis, J. Eng. Gas Turbines Power. 139 (2017).

[29]F. He, S. Dousti, P. Allaire, M. Dousti, Squeeze film damper effect on vibration of an unbalanced flexible rotor using harmonic balance method, J. Eng. Sci. Technol. 12 (2017).

[30]H. Chen, Y. Chen, L. Hou, Z. Li, Bifurcation analysis of rotor-squeeze film damper system with fluid inertia, Mech. Mach. Theory. 81 (2014). 


\section{Supplementary Files}

This is a list of supplementary files associated with this preprint. Click to download.

- Declaration.docx

- Highlights.docx 